\title{
Surface Integrity and Structural Stability of Broached Inconel 718 at High Temperatures
}

\author{
Zhe Chen, Ru Peng, Johan Moverare, P. Avdovic, J. M. Zhou and Sten Johansson
}

\author{
Linköping University Post Print
}

\section{Tweet}

N.B.: When citing this work, cite the original article.

The original publication is available at www.springerlink.com:

Zhe Chen, Ru Peng, Johan Moverare, P. Avdovic, J. M. Zhou and Sten Johansson, Surface Integrity and Structural Stability of Broached Inconel 718 at High Temperatures, 2016, Metallurgical and Materials Transactions. A, (47A), 7, 3664-3676.

http://dx.doi.org/10.1007/s11661-016-3515-6

Copyright: Springer Verlag (Germany)

http://www.springerlink.com/?MUD=MP

Postprint available at: Linköping University Electronic Press

http://urn.kb.se/resolve?urn=urn:nbn:se:liu:diva-130060 
Surface Integrity and Structural Stability of Broached Inconel 718 at High Temperatures

Z. Chen ${ }^{\text {a, }}{ }^{*}$, R. Lin Peng ${ }^{\text {a }}$, J. Moverare ${ }^{\text {a }}$, P. Avdovic ${ }^{\text {b }}$, J.M. Zhou ${ }^{\text {c }}$, S. Johansson ${ }^{\text {a }}$

a Division of Engineering Materials, Linköping University, 58183 Linköping, Sweden

b Siemens Industrial Turbomachinery AB, 61283 Finspång, Sweden

${ }^{\mathrm{c}}$ Division of Production and Materials Engineering, Lund University, 22100 Lund, Sweden

* Corresponding author Tel.: +46 13281784 Fax: +46 13282505 Email address: zhe.chen@liu.se

\section{Abstract}

The current study focused on the surface integrity issues associated with broaching of Inconel 718 and the structural stability of the broached specimen at high temperatures, mainly involving the microstructural changes and residual stress relaxation. The broaching operation was performed using similar cutting conditions as that used in turbo machinery industries for machining fir-tree root fixings on turbine disks. Thermal exposure was conducted at $723 \mathrm{~K}, 823 \mathrm{~K}$ and $923 \mathrm{~K}$ (450 ${ }^{\circ} \mathrm{C}, 550{ }^{\circ} \mathrm{C}$ and $650{ }^{\circ} \mathrm{C}$ ) for 30,300 and 3000 hours, respectively. Surface cavities and debris dragging, sub-surface cracks, high intensity of plastic deformation, as well as the generation of tensile residual stresses were identified to be the main issues in surface integrity for the broached Inconel 718. When a subsequent heating was applied, surface recrystallization and $\alpha-\mathrm{Cr}$ precipitation occurred beneath the broached surface depending on the applied temperature and exposure time. The plastic deformation induced by the broaching is responsible for these microstructural changes. The surface tension was completely relaxed in a short time at the temperature where surface recrystallization occurred. The tensile layer on the sub-surface, however, exhibited a much higher resistance to the stress relief annealing. Oxidation is inevitable at high temperatures. The study found that the surface recrystallization could promote the local $\mathrm{Cr}$ diffusion on the broached surface. 
Keywords: Surface integrity, Broaching, Inconel 718, Thermal exposure, Recrystallization, $\alpha-\mathrm{Cr}$ precipitation, Stress relaxation

\section{Introduction}

Inconel 718 is a Ni-based superalloy that is widely used as a disk material in the hot sections of turbine engines, owing to its superior mechanical properties and its high resistance to oxidation/corrosion at elevated temperatures. The alloy is predominantly strengthened by the precipitate gamma double prime $\left(\gamma^{\prime \prime}-\mathrm{Ni}_{3} \mathrm{Nb}\right)$ which appears as disc-shape particles with a coherent relationship with the $\gamma$ matrix [1]. The microstructure of Inconel 718 degrades when exposed to temperatures above $923 \mathrm{~K}\left(650{ }^{\circ} \mathrm{C}\right)$. The $\gamma^{\prime \prime}$ phase transforms to incoherent $\delta$ phase and the mechanical properties deteriorate rapidly [2]. Meanwhile, for long-term applications, other precipitates such as $\alpha$-Cr and $\sigma$ could also form [3]. The formation and growth of $\alpha$-Cr has been reported to be partly responsible for the significant drop in impact strength of Inconel 718 [4]. The good oxidation/corrosion resistance of the alloy at high temperatures is provided by a high chromium content which allows a protective surface chromia scale to be developed in most atmosphere [5,6,7].

Machining of Inconel 718 has always been a challenge. Due to its high strength, the cutting forces attain high values, while the low thermal conductivity leads to high cutting temperatures being developed in the cutting zone. The high chemical affinity of the alloy to many tool materials and its sensitivity to strain rate can also cause rapid wear of the cutting tools and work hardening of the machined workpiece. Ulutan and Ozel [8] published a review paper with a focus on the machininginduced surface integrity in titanium and nickel alloys in which they pointed out that the need of attention in machined Inconel 718 mainly involves surface tearing, cavities, micro-cracks, dynamic recrystallization, plastic deformation, work hardening, and the formation of residual stresses. 
High intensity of plastic deformation is generally perceived to be a main threat to surface integrity [9]. Bushlya et al. [10] suggested that in high speed turning of Inconel 718, the giant temperature gradients imposed on the greatly deformed surface material could even lead to the formation of a white layer. Imran et al. [11] also observed the white layer for a micro-drilling process for Inconel 718 and the thickness increased slightly with increasing feed rate and cutting speed. The presence of a surface white layer has been found to significantly reduce the fatigue life because of the loss of ductility in this layer [12]. Another one of the most relevant practical parameters that is commonly used for evaluating the quality of a machined surface is residual stress. Peng et al. [13] measured the residual stresses in Inconel 718 induced by turning. The results revealed that the high cutting heat generated at the machined surface was responsible for the formation of surface tensile residual stresses, and increased surface tension usually was obtained as the cutting temperature was raised, e.g., turning at increased cutting speeds or using worn tools. A similar phenomenon was observed by Sharman et al. $[14,15]$ where the use of coated tools, the increased tool nose radius, the higher cutting speed, and larger feed rate were found to lead to an increase in the surface tensile stresses.

In turbo machinery industries, one of the last manufacturing steps for turbine disks is to broach blade root fixings, commonly of fir-tree design. These broached fir-tree root fixings normally represent the most critical region of a turbine disk from the point of view of fatigue failures. Witek [16] performed an analysis on a failed turbine disk and found that a fatigue crack originated from the surface at the corner of the lower tooth of a fixing that eventually caused the catastrophic fracture, resulting in the separation of the entire fixing from the disk.

Compared with the other cutting processes, little work has been published on broaching even though it has significant industrial importance. The influence of cutting variables on the surface integrity and broaching forces has been investigated by Mo et al. [17] when broaching heat- 
resistant alloys. Some other issues of broaching were also reported in relation to modeling of cutting temperature [18], tool condition monitoring [19], coolant effect on surface finish [20], dynamics of broaching [21] and machining accuracy [22]. Most of the studies that have been done on broaching so far are primarily concerned with the cutting process and tool wears. Even though some investigations have paid attention to the surface integrity of broached components, the studied materials rarely included Inconel 718. Klocke et al. [23] investigated the broaching of Inconel 718 with cemented carbide cutting tools, and compared its performance with that produced by traditional high speed steels in terms of tool wears, cutting forces, and surface integrity. An overview of the plastically deformed microstructure produced by the broaching process was given by using optical microscope, but the residual stresses generated at the broached surface were not covered in the study.

None of the previously published papers have systematically studied the surface integrity of broached Inconel 718 and also evaluated its structural stability, in terms of microstructure and residual stresses, at elevated temperatures. When thermal loads are applied, the mechanical energy stored at the machined surface tends to lead to microstructure changes of the material. The occurrence of the microstructural alteration will inevitably result in changes in mechanical properties as well as residual stress state which is of great importance to the high temperature application of turbine disks where high fatigue resistance and tight tolerance in dimensions are strongly required.

The aim of the present work is to cover the lack of studies of broached Inconel 718 as described above. The broaching operation used in this study is similar to that employed in turbo machinery industries for producing fir-tree root fixings on turbine disks. The typical service temperature for Inconel 718 turbine disks is covered in the chosen temperature range as well. Therefore, the results 
could also give a better understanding of the fatigue failure mechanism on gas turbine disks from the machining point of view.

\section{Experimental procedure}

\subsection{Material}

The broaching was carried out on an Inconel 718 coupon $\left(200 \times 200 \times 50 \mathrm{~mm}^{3}\right)$ taken from the forging used for the production of turbine disks. The chemical composition is given in Tab. 1. The forging was solution annealed at $1243 \mathrm{~K}\left(970{ }^{\circ} \mathrm{C}\right)$ for 3.5 hours, and then air cooled to room temperature, followed by aging for 8 hours at $993 \mathrm{~K}\left(720^{\circ} \mathrm{C}\right)$ and further for 8 hours at $893 \mathrm{~K}(620$ ${ }^{\circ} \mathrm{C}$ ), finally air cooled to room temperature. The resulting microstructure is shown in Fig. 1.

\subsection{Specimens}

Notches were machined at the rim of the coupon using a broaching process similar to that used for machining turbine blade root fixings. The broached notch with a fir-tree profile is presented in Fig. 2. The broach used in this study is made of PM-T15 high speed steel (65 - 67 HRC) with semiworn conditions, and the rise-per-tooth for roughing, semi-finishing, and finishing section is 0.066, 0.054 to 0.038 , and $0.013 \mathrm{~mm}$ respectively. The semi-worn condition is defined from the industrial point of view as that the tool has been used for several broaching of disks, while it can still keep the required dimension tolerance. The cutting angle was kept constant at 12 deg of rake angle and 3 deg of clearance angle. The cutting speed was fixed at $V c=3 \mathrm{~m} / \mathrm{min}$. Broaching oil as cooling lubricant was employed throughout the entire broaching process.

Broached specimens were extracted by wire-cut electric discharge machining. One specimen was kept in the as-broached condition; the others were thermally exposed in air at $723 \mathrm{~K}, 823 \mathrm{~K}$ and $923 \mathrm{~K}\left(450{ }^{\circ} \mathrm{C}, 550{ }^{\circ} \mathrm{C}\right.$ and $650{ }^{\circ} \mathrm{C}$ ) for respectively 30, 300, and 3000 hours. All subsequent microstructure characterization, residual stress measurements, and nano-indentation were conducted beneath the lower broached surface of the second tooth, as indicated in Fig. 2, on which 
turbine blades are in intimate contact with the disk during the service of a turbine engine due to large centripetal forces.

\subsection{Microscopy}

For microscopy, specimens were cross-sectioned along the broaching direction, mounted, and polished. A Hitachi SU-70 scanning electron microscope (SEM), operating at 1.5 to $20 \mathrm{kV}$, was used together with electron channeling contrast imaging (ECCI) [24], electron backscatter diffraction (EBSD) and energy-dispersive X-ray spectroscopy (EDX) to characterize the appearance of the broaching-induced surface and sub-surface microstructure and also the microstructure beneath the broached surface after heating.

\subsection{Residual stress measurement}

Residual stress measurements were made by X-ray diffraction using a four-circle Seifert X-ray diffractometer equipped with a linear position-sensitive detector. $\mathrm{Cr}-\mathrm{K}_{\alpha}$ radiation was chosen, giving a high diffraction peak at $2 \theta \sim 128$ deg for the $\{220\}$ family of lattice planes of the nickelbased matrix. Two in-plane stress directions were measured on the broached surface, i.e., broaching direction (BD) and transverse direction (TD), corresponding to $\sigma_{11}$ and $\sigma_{22}$ as illustrated in Fig. 3; residual stresses were calculated based on the " $\sin ^{2} \psi$ " method [25] with an X-ray elastic constant of $4.65 \times 10^{-6} \mathrm{MPa}^{-1}$. When necessary (e.g. for triaxial stress analysis), the $45^{\circ}$ in-plane stress direction was measured from which, together with the other two directions, two out-plane shear components ( $\sigma_{13}$ and $\sigma_{23}$ ) can be calculated. All depth profiles were obtained using electrolytic polishing with Struers LectroPol-5.

\subsection{Nano-indentation}

On the as-broached specimen, nano-indentation was performed to obtain the nano-hardness depth profile from the broached surface to the bulk. Five measurements were taken on the polished cross section at each depth by applying a constant load of $50 \mathrm{mN}$ with 30 seconds holding time. 


\section{Results}

3.1 Surface integrity of as-broached Inconel 718

\subsubsection{Surface morphology}

Although a good surface finish in terms of surface roughness with $\mathrm{Ra}=0.35 \mu \mathrm{m}$ was produced using the broaching condition described, a close observation under SEM still revealed various forms of surface anomalies on the machined surface, see Fig. 4. Broaching marks as coarse-scale surface irregularities [26] were in parallel to the cutting direction. Also material side flow was observed in the area of the broaching marks where a large part of the plastically deformed workpiece material was plowed aside when the chip thickness was less than the minimum thickness $\left(t_{\text {min }}\right)$ [27]; it is facilitated by high temperatures in the cutting zone. The cracking and breakage of carbide particles resulted in appreciable cavities as well as debris dragging on the broached surface.

\subsubsection{Plastic deformation}

Fig. 5 shows the microstructure beneath the broached surface on the cross-sectioned specimen. A layer with barely resolvable microstructure under low magnification in SEM was formed at the surface; only a few $\delta$ phase fragments can be observed. The thickness of this layer is approximately 3 to $5 \mu \mathrm{m}$. On the sub-surface, the material was highly plastically deformed in the broaching direction, as indicated by shearing and elongation of the grain boundaries and $\delta$ phases. The intensity of the plastic deformation was decreased as the depth increased, but still one could see a large amount of deformed grains with slip bands lying in different orientations. As a consequence of the large plastic strain, cracked carbides were observed, see Fig. 6. It is also possible to see the propagation of the crack initiated from a carbide along the surface layer.

In Fig. 7, nano-hardness vs the depth from the broached surface is plotted together with the lowangle grain boundary (LAGB) density depth profile measured by EBSD. The nano-hardness was found to be greater close to the surface than through the depth of the material. The work-hardened 
layer was extended to a depth of $\sim 45 \mu \mathrm{m}$ which is roughly identical to the thickness of the zone with an increased LAGB density. It suggests that the work-hardened layer was formed in response to the machining-induced plastic deformation beneath the surface.

\subsubsection{Residual stresses}

The residual stress depth profile of the as-broached specimen is shown in Fig. 8. The broaching operation generated high tensile residual stresses at the machined surface, both for $\sigma_{11}$ and $\sigma_{22}$. In the sub-surface region, a layer exhibiting tensile residual stresses was formed, followed by a layer with compressive residual stresses that is several times thicker than the tensile layer. The stress component $\sigma_{11}$ showed a higher value in tension with a peak tensile stress of $727 \mathrm{MPa}$ in comparison with that of $270 \mathrm{MPa}$ for $\sigma_{22}$. The sub-surface compressive layer extended to a depth of $\sim 200 \mu \mathrm{m}$ with a similar peak stress in both two directions.

The breadth of the diffraction peak (i.e. Full Width at Half Maximum Intensity (FWHM)) as function of depth is also given in Fig. 8. The maximum value appeared on the surface followed by a fast drop within the depth of $\sim 50 \mu \mathrm{m}$ and then gradually decreased to the plateau in accordance with the level of the bulk material.

\subsection{Effect of thermal exposure}

\subsubsection{Microstructure}

Fig. 9 gives a set of ECCI images overviewing the microstructural evolution on the broached surface and sub-surface with the increased heating temperature and exposure time. It should be noted that an oxide scale was formed on the broached surface when the specimens were heated, but it was invisible in ECCI images when the image contrast was increased to better visualize the broached alloy beneath. Therefore, the surface observed is the oxide/metal interface or the broached surface, not the top surface. The oxidation behavior will be discussed later in this paper. 
Fig. 9(a) is served as a reference from which it is clear that the surface layer underwent a process of recrystallization after thermal exposure and its degree was strongly dependent on the heating condition applied. The effect of heating temperature was significant. For the 3000 hours specimens, see Fig. 9(b), (e), and (h), generally there were no recrystallized grains at $723 \mathrm{~K}\left(450{ }^{\circ} \mathrm{C}\right)$, whereas when $823 \mathrm{~K}\left(550{ }^{\circ} \mathrm{C}\right)$ was applied, a large amount of small grains can be seen in the surface layer and a fast grain growth took place as the temperature was raised to $923 \mathrm{~K}\left(650{ }^{\circ} \mathrm{C}\right)$. On the other hand, when the temperature was constant at $823 \mathrm{~K}$ or $923 \mathrm{~K}\left(550^{\circ} \mathrm{C}\right.$ or $\left.650{ }^{\circ} \mathrm{C}\right)$ for longer exposure time, an increased level of recrystallization was observed, see for example in Fig. 9(c) through (e) or Fig. 9(f) through (h). The surface layer that has been thermally exposed also consists of a number of $\delta$ phase particles which may either originate from the $\delta$ phase fragments formed in broaching or precipitate during the heat treatment.

In Fig. 9, another microstructural change that can be identified is the precipitation of a plenty of small particles, mostly in the vicinity of the $\delta$ phase, beneath the broached surface. A combination of EBSD mapping and EDS mapping, see Fig. 10, reveals that the precipitates have a body-centered cubic crystal structure with high content of $\mathrm{Cr}$, revealing $\alpha$-Cr phase identification which is in agreement with the indexed Kikuchi pattern.

For the specimen heated at $723 \mathrm{~K}\left(450{ }^{\circ} \mathrm{C}\right)$, see Fig. 9(b), the $\alpha$-Cr precipitation was predominately concentrated in the surface layer with a dispersive distribution. When the specimens were subjected to thermal exposure at $823 \mathrm{~K}\left(550{ }^{\circ} \mathrm{C}\right)$, not only the surface precipitation, $\alpha$-Cr also started to emerge in sub-surface as seen in Fig. 9(c) through (e), but it is noted that at $823 \mathrm{~K}\left(550{ }^{\circ} \mathrm{C}\right)$ the short-time (i.e., 30 and 300 hours respectively) heating caused only very few $\alpha$-Cr precipitated in sub-surface, whereas the fraction was dramatically increased for the 3000 hours long-time exposure. In contrast, appreciable $\alpha$-Cr precipitates were found in the sub-surface only after 30 hours short- 
time heating as the temperature was further increased to $923 \mathrm{~K}\left(650{ }^{\circ} \mathrm{C}\right)$, see Fig. $9(\mathrm{f})$, and they grew in size with the increased exposure time, see Fig. 9(g) and (h).

Although a large number of $\alpha$-Cr have been found to precipitate in the surface layer and sub-surface, from Fig. 9 one can observe a zone formed at the broached surface of the heat-treated specimens where the $\alpha$-Cr precipitates were absent, while the size of this zone was temperature and time dependent. For instance, Fig. 11 shows the expansion of the $\alpha$-Cr free zone as a consequence of the increased heating temperature.

\subsubsection{Surface residual stresses}

In Fig. 12, the change in terms of surface residual stresses and surface FWHM is plotted for all temperatures and time applied; generally they dropped with the increased heating temperature and the longer exposure time. At the relatively low temperature, i.e., $723 \mathrm{~K}\left(450{ }^{\circ} \mathrm{C}\right)$, the surface tension was partially reduced and the amplitude was dependent on the heating time. At $823 \mathrm{~K}\left(550{ }^{\circ} \mathrm{C}\right), 30$ hours thermal exposure was observed to give complete relaxation of the surface tension, and then as the heating time was further increased, surface compression appeared. At the highest temperature, i.e., $923 \mathrm{~K}\left(650{ }^{\circ} \mathrm{C}\right)$, all heat treatments completely removed the broaching-induced surface tension and left compressive residual stresses at the surface with a similar level independent on the exposure time applied. However, the surface FWHM kept decreasing with the increased time as the same as the trend observed at $723 \mathrm{~K}$ and $823 \mathrm{~K}\left(450{ }^{\circ} \mathrm{C}\right.$ and $\left.550{ }^{\circ} \mathrm{C}\right)$.

\section{Discussions}

\subsection{Surface integrity generated in broaching}

A wide variety of issues in surface integrity were generated during broaching of Inconel 718 among which surface cavities and sub-surface cracks, high intensity of plastic deformation, and the formation of tensile residual stresses are considered to be most detrimental from the fatigue point of view. In most cases, the cavities and cracks were initiated from the cracking and breakage of the 
carbide particles which were unable to deform to the same extent as the plasticized layer on the surface and sub-surface.

In Fig. 5, the feature of the surface layer that is barely resolvable under SEM indicates the presence of a white layer. With assistance of the ECCI, see Fig. 13, it shows that the surface layer consists of a nano-crystalline structure, which is consistent with the microstructure characterization performed by Bushlya et al. [10] on the white layer generated in turning of Inconel 718 alloys. They pointed out that considerable plastic deformation is the predominant one out of the three possible mechanisms suggested by Griffiths [28] which are responsible for the formation of the surface white layer. High cutting speeds, the use of worn tools, and dry cutting usually lead to substantial plastic deformation on the machined surface because of the high cutting temperature generated [29]. A study, performed by Barry and Byrne [30], further suggested that surface white layer generation with high plastic deformation is essentially an adiabatic shear process aided by the high local cutting temperature. From Fig. 5, it is clear that the broaching caused large shear deformation of the material as the sub-surface microstructure was sheared and elongated towards the broaching direction. However, adiabatic shearing only occurred in a few microns of the surface layer where the material was subjected to the most intensive deformation and the highest cutting temperature. The calculation of the two out-plane shear components ( $\sigma_{13}$ and $\sigma_{23}$ ), as plotted in Fig. 14, to some extent, also reveals the great tensile shear deformation along the broaching direction at the surface; the compressive residual stress in the shear component, $\sigma_{13}$, therefore, was generated during the cooling.

Residual stresses in machining operations have been recognized to originate from plastic deformation and local temperature increase [31]. Mechanical plastic deformation primarily results in compressive stresses, while significant cutting heat input normally leads to tensile stresses in a surface layer due to the constrain from the cold bulk to the expansion of the surface layer; once 
local yielding takes place, tensile residual stresses will form during the cooling. With the formation of the surface tension and near-surface tensile layer, as shown in Fig. 8, the residual stresses generated in the as-broached specimen appears to be of thermal origin. However, the compressive layer in the deeper sub-surface was nearly triple in thickness compared with the tensile layer, while the depth that the compressive residual stresses reached was comparable to the depth with increased FWHM. In case of machining, FWHM is perceived to be a good indicator of cutting-induced plastic strains [32]. Thus, the sub-surface compressive residual stresses were mainly initiated from the mechanical plastic deformation associated with cutting forces and the high cutting heat led to thermal-induced plastic deformation on the surface and near surface, thereby changing the top layer to tension.

The formation of white layer as well as surface tension in machining have a direct correlation to the high temperature at the cutting edge. Cutting speeds is one of the most relevant parameters that can determine the temperature generated in machining; generally an increased cutting speed gives rise to a higher cutting temperature. It is noted that unlike other cutting processes e.g., turning in which a high cutting speed, even up to a few hundred meters per min or even above $100 \mathrm{~m} / \mathrm{min}$., can be achieved, to ensure the surface finish and dimension tolerance, when broaching Ni-based superalloys with high speed steel tools the cutting speed is usually limited in a range of 2 to 8 $\mathrm{m} / \mathrm{min}$.

The broaching process applied in this study was performed at $3 \mathrm{~m} / \mathrm{min}$. Our observation that a white layer was formed and high surface tensile residual stresses were generated on the broached surface indicates that the broaching still can bring surface integrity issues associated with the high cutting temperature at such low cutting speed under coolant. In broaching, it is important that there are always at least two, preferable more cutting edges in contact at any one time. Considering in multi-points cutting each cutting edge acts as an independent heat source due to the plastic work 
and friction [33], large heat accumulation, and consequent high plastic deformation due to material softening, therefore, can be expected on the broached surface. The semi-worn condition of the broach further exacerbated the heat generation.

\subsection{Recrystallization and stress relaxation}

From the EBSD mapping of the annealing twin formed on the broached surface of the specimen been heated at $923 \mathrm{~K}\left(650{ }^{\circ} \mathrm{C}\right)$ for 3000 hours, see Fig. 15, it is clear that the highly deformed microstructure in the white layer was recrystallized after thermal exposure; annealing twins appeared as a consequence of growth accidents, whereas no recrystallization occurred in the subsurface area with less plastic deformation, see Fig. 16(b). The occurrence of static recrystallization in a component is dependent on the strain prior induced into the material as well as the annealing condition applied. From Fig. 9, it has shown that the heat treatment at $823 \mathrm{~K}\left(550{ }^{\circ} \mathrm{C}\right)$ was enough to trigger the recrystallization of the white layer on the broached surface.

As discussed above, residual stresses generated in machining are primarily associated with the plastic strains either induced by cutting forces or by local temperature increase. The EBSD mappings in Fig. 16 provide information concerning the annihilation of LAGBs in the surface layer where the recrystallization took place. Therefore, when the annealing temperature lies in the region of the recrystallization temperature, complete relaxation of the surface residual stresses induced by broaching can be expected. Hence, it is rational that after 30 hours thermal exposure at $823 \mathrm{~K}$ (550 ${ }^{\circ} \mathrm{C}$ ), the surface tensile residual stresses were found to be completely removed, as shown in Fig. 12. Another parameter that can indicate the elimination of the broaching-induced dislocations as the consequence of the surface recrystallization is the decreasing value of surface FWHM, see Fig. 12. The sharp drop in the value of surface FWHM for the specimen exposed at $823 \mathrm{~K}\left(550{ }^{\circ} \mathrm{C}\right)$ for 30 hours and for 300 hours shows that the highly deformed microstructure on the broached surface was, to a large extent, replaced by dislocation-free recrystallized grains. It is consistent with the 
microstructure observations, as shown in Fig. 9(c) and (d). With further extension of the exposure time or temperature increase to $923 \mathrm{~K}\left(650{ }^{\circ} \mathrm{C}\right)$, because of the fully recrystallized surface microstructure, the broaching-induced plastic deformation had no longer effect on the surface FWHM or the surface stress state. The compressive residual stresses measured on the specimens are believed to originate from the cooling. The continuous slight decrease in surface FWHM, on the other hand, was probably governed by the growing grain size.

In addition, an interesting observation was that at $723 \mathrm{~K}\left(450^{\circ} \mathrm{C}\right)$ with negligible recrystallization in the white layer as the exposure time increased the surface peak broadening was also gradually decreased with a simultaneous relaxation of the surface tensile residual stresses. It could be explained by the pre-recrystallization phenomenon [34] during which the strain energy is released prior to recrystallization by the movement and rearrangement of dislocations within piled-up groups. Mutual annihilation of dislocations with opposite sign occurs in this process.

In contrast to the great relaxation of the surface tension, the thermal exposure had a less effect in terms of eliminating the sub-surface tensile layer, see Fig. 17, for $823 \mathrm{~K}\left(550{ }^{\circ} \mathrm{C}\right)$ and 30 hours. $923 \mathrm{~K}\left(650{ }^{\circ} \mathrm{C}\right)$ was found to be sufficient to remove the broaching-induced tensile layer if longtime exposure was applied, see Fig. 18, but the heat treatment caused rapid coarsening of the $\gamma^{\prime \prime}$ phase, see Fig. 9(h), which is problematic to mechanical properties. Vöhringer [35] stated that the thermally activated residual stress relaxation strongly relies on the dislocation cross slip. However, Inconel 718 is a typical alloy with low stacking fault energy where cross slip of dislocations is restricted and the mobility of dislocations is also reduced as the consequence of the presence of numerous solute atoms and precipitates. Our finding suggests that for Inconel 718, if tensile residual stresses are generated during machining, they are difficult to be removed by subsequent stress relief annealing or self-relaxed during the service at elevated temperatures which do not 
induce extensive recrystallization. Surface treatment, e.g., shot-peeing which can introduce beneficial compressive residual stresses, might be necessary if a high fatigue resistance is required. $4.3 \alpha-$ Cr precipitation

Bi et al. [36] suggested that the precipitation of $\alpha$-Cr phase in Inconel 718 is strongly associated with the growth of the $\delta$ phase during which a continued rejection of $\mathrm{Cr}$ occurs, leading to $\mathrm{Cr}$ segregation in the vicinity of the $\delta$ particles. It explains the observation that most Cr precipitates formed beneath the broached surface during thermal exposure were adjacent to the $\delta$ phase, see Fig. 9.

$\alpha$-Cr is considered to be a natural site of mechanical weakness and normally forms in Inconel 718 after long-term thermal exposure at temperatures above $923 \mathrm{~K}\left(650{ }^{\circ} \mathrm{C}\right)$, e.g., at $923 \mathrm{~K}\left(650{ }^{\circ} \mathrm{C}\right), \alpha$ Cr appears at a minimum of 1000 hours [3]. Previous work by the authors [37] has demonstrated that $\alpha$-Cr formed beneath the broached surface at $923 \mathrm{~K}\left(650{ }^{\circ} \mathrm{C}\right)$ after 300 hours; the shorter time for the appearance of the $\alpha$-Cr phase was linked to the higher $\mathrm{Cr}$ diffusion in the $\gamma$ matrix owing to the benefit of the broaching-induced dislocations. Unlike at the temperature above $923 \mathrm{~K}\left(650{ }^{\circ} \mathrm{C}\right)$, $\alpha$-Cr precipitation rarely takes place below $873 \mathrm{~K}\left(600{ }^{\circ} \mathrm{C}\right)$ since the formation and growth of the $\delta$ phase is negligible [38]. However, surprisingly appreciable $\alpha$-Cr particles were still observed when the broached specimen was heated at $823 \mathrm{~K}\left(550^{\circ} \mathrm{C}\right)$, in particular for the one with the longest 3000 hours exposure time, see Fig. 9(e), from which it reveals an enhanced tendency in terms of the $\delta$ precipitation beneath the broached surface. One possible reason is that $\mathrm{Nb}$ segregated at the deformation bands or dislocations, which might be similar to the grain boundary segregation of $\mathrm{Nb}$ in Inconel 718 [39]. The surface white layer formed with much more intensive plastic deformation compared to the sub-surface. Hence, as the continuous decrease of the heating temperature to 723 $\mathrm{K}\left(450{ }^{\circ} \mathrm{C}\right)$, the $\alpha$-Cr precipitates only emerged in the surface layer despite the exposure time was prolonged to 3000 hours, see Fig. 9(b). 


\subsection{Oxidation behavior}

From the observation in Fig. 11, close to the broached surface a layer with depletion of the $\alpha-\mathrm{Cr}$ was created and it expanded inwards from the surface as the temperature increased. It can be rationalized by the oxidation attack since at elevated temperatures alloys like Inconel 718 are known to form protective $\mathrm{Cr}_{2} \mathrm{O}_{3}$ on the top surface under the atmospheric environment [7]. In good agreement, there was a continuous oxide scale which is Cr-rich formed on the top of the broached surface after the heat treatments in this study; the oxide layer as mentioned above cannot be visualized in the ECCI images, but a secondary electron image, taken from the specimen exposed at $923 \mathrm{~K}\left(650{ }^{\circ} \mathrm{C}\right)$ for 3000 hours, is presented in Fig. 19.

The generation of the Cr-rich oxide scale on the top of the broached surface no doubt will consume a proportion of the $\mathrm{Cr}$ in the region close to the surface. The $\mathrm{Cr}$ depth profile measured on the metallic alloy below the oxide scale for the broached specimen with 300 hours heat treatment at $923 \mathrm{~K}\left(650^{\circ} \mathrm{C}\right)$ successfully captures the reduction of the Cr content within a few microns beneath the broached surface, see Fig. 20. It is very likely that close to the surface the local Cr segregation in the vicinity of the $\delta$ phase was effectively offset by the consumption of the Cr due to the oxidation attack, therefore leaving a zone without $\alpha$-Cr appearance, and this depletion zone became larger when more aggressive oxidation took place either at a higher heating temperature or with longer exposure time.

The present study also shows that the Cr diffusivity on the broached surface was dramatically increased as evident by the surface plateau in Fig. 20. This can be compared to the variation in $\mathrm{Cr}$ content below the oxide scale for a polished specimen, without any broaching effect, after 300 hours heat treatment at $923 \mathrm{~K}\left(650{ }^{\circ} \mathrm{C}\right)$ in air where the $\mathrm{Cr}$ content decreases sharply when approaching the polished surface with a much lower value than that obtained from the plateau. It suggests that at this temperature, for the polished specimen, once the surface Cr is consumed by 
oxidation, it could hardly be compensated through a diffusion of the interior Cr atoms. On the other hand, for the broached specimen, the surface comprised substantial refined grains which provide a great number of grain boundaries. It is well known that grain boundaries exhibit distinctive properties, e.g., high diffusivity, based on its character [40,41]. With a higher diffusivity, more interior $\mathrm{Cr}$ atoms would be able to diffuse to the broached surface to compensate the consumption of the Cr. Machining-induced residual stress may also affect the diffusion of atoms in the direction perpendicular to the machined surface [42]. However, in the case when surface recrystallization occurs, its effect would probably be minor because of the great stress relaxation.

\section{Conclusions}

A broaching operation similar to that used for machining fir-tree root fixings in the turbo machinery industry has been performed on an Inconel 718 forging with the purpose of investigating the surface integrity issues that one has to consider when manufacturing turbine disks. The broached specimens were subsequently heat treated at high temperatures to study the microstructural changes, residual stress relaxation, as well as their correlations. The following conclusions can be drawn from this work.

- Surface cavities and debris dragging, sub-surface cracks, high intensity of plastic deformation, and the generation of tensile residual stresses are the main issues in surface integrity identified in the broached Inconel 718. There is a significant thermal impact during the broaching as evident by the formation of a white layer and the surface tension despite the fact that the cutting speed applied is as low as $3 \mathrm{~m} / \mathrm{min}$ and coolant is applied.

- There is a tendency for the surface white layer to undergo a restoration process of recrystallization when subjected to high temperatures. The heat treatment at $823 \mathrm{~K}$ (550 ${ }^{\circ} \mathrm{C}$ ) for 3000 hours is enough to trigger full recrystallization, while a shorter time is required as the temperature is further increased to $923 \mathrm{~K}\left(650{ }^{\circ} \mathrm{C}\right)$. 
- The surface tension can be completely relaxed in a short time at the temperature where surface recrystallization occurs which is associated with rearrangement of the dislocations or with annihilation of the plastic strain. In contrast, the relaxation of the sub-surface tensile residual stresses is sluggish for temperatures lower than $923 \mathrm{~K}\left(650{ }^{\circ} \mathrm{C}\right)$. At $923 \mathrm{~K}(650$ ${ }^{\circ} \mathrm{C}$ ), the stress relaxation is considerable, whereas coarsening of the $\gamma^{\prime \prime}$ occurs.

- Microstructural degradation of Inconel 718, in the form of $\alpha$-Cr precipitation, takes place beneath the broached surface for all temperatures applied. It could be attributed to the enhanced tendency of the $\delta$ precipitation and the faster $\mathrm{Cr}$ diffusion in the $\gamma$ matrix. Both mechanisms originate from the broaching-induced plastic deformation.

- The recrystallization on the broached surface seems to promote the local Cr diffusion, in such a way that the consumption of the $\mathrm{Cr}$ at the surface due to oxidation, to some extent, can be compensated.

\section{Acknowledgments}

The authors would like to thank Ms. Annethe Billenius from Linköping University, for the help with the laboratory work, Agora Materiae, Faculty Grant SFO-MAT-LiU\#2009-00971 at Linköping University, Siemens Industrial Turbomachinery AB for their valuable supports. 


\section{References}

[1] D.F. Paulonis, J.M. Oblak, and D.S. Duvall: Trans. Quart. ASM, 1969, vol. 62, pp. 611-622.

[2] J.W. Brooks and P.J. Bridges: Superalloys, pp. 33-42, TMS, Warrendale, 1988.

[3] A. Oradei-Basile and J. F. Radavich: Superalloys 718, 625 and Various Derivatives, pp. 325335, TMS, Warrendale, 1991.

[4] X. Xie, G. Wang, J. Dong, C. Wu, J. Radavich, G. Shen, and B.A. Lindsley: Superalloys 718, 625 and Various Derivatives, pp. 399-410, TMS, Warrendale, 2001.

[5] L. Jian, C.Y. Yuh, and M. Farooque: Corros. Sci., 2000, vol. 42, pp. 1573-1585.

[6] L. Geng, Y. Na, and N. Park: Mater. Des., 2007, vol. 28, pp. 978-981.

[7] G.A. Greene and C.C. Finfrock: Oxid. Met., 2001, vol. 55, pp. 505-521.

[8] D. Ulutan and T. Ozel: Int. J. Mach. Tools Manuf., 2011, vol. 51, pp. 250-280.

[9] E.O. Ezugwu, Z.M. Wang, and C.L. Okeke: Tribol. Trans., 1999, vol. 42, pp. 353-360.

[10] V. Bushlya, J.M. Zhou, F. Lenrick, P. Avdovic, and J.E. Ståhl: Procedia Engineering, 2011, vol. 19, pp. 60-66.

[11] M. Imran, P.T. Mativenga, A. Gholinia, and P.J. Withers: Int. J. Adv. Manuf. Technol., 2011, vol. 55, pp. 465-476. 
[12] A.M. Wusatowska-Sarnek, B. Dubiel, A. Czyrska-Filemonowicz, P.R. Bhowal, N.B. Salah, and J.E. Klemberg-Sapieha: Metall. Mater. Trans. A, 2011, vol. 42, pp. 3813-3825.

[13] R.L. Peng, J.M. Zhou, S. Johansson, A. Bellinius, V. Bushlya, and J.E. Ståhl: HTM Journal of Heat Treatment and Materials, 2014, vol. 69, pp. 46-53.

[14] A.R.C. Sharman, J.I. Hughes, and K. Ridgway: J. Mater. Process. Technol., 2006, vol. 173, pp. 359-367.

[15] A.R.C. Sharman, J.I. Hughes, and K. Ridgway: J. Mater. Process. Technol., 2015, vol. 216, pp. 123-132.

[16] L. Witek: Eng. Failure Anal., 2006, vol. 13, pp. 9-17.

[17] S.P. Mo, D.A. Axinte, T.H. Hyde, and N.N.Z. Gindy: J. Mater. Process. Technol., 2005, vol. 160, pp. 382-389.

[18] S. Gierlings and M. Brockmann: Advanced Materials Research, 2013, vol. 769, pp. 139-146.

[19] D.A. Axinte and N. Gindy: Wear, 2003, vol. 254, pp. 370-382.

[20] N.F. Suchkov and V.N. Latyshev: Machines Tooling, 1973, vol. 44, pp. 49-50.

[21] D. Axinte: Int. J. Mach. Tools Manuf., 2007, vol. 47, pp. 2182-2188.

[22] V. Sajeev, L. Vijayaraghavan, and U.R.K. Rao: Int. J. Mech. Eng. Educ., 2000, vol. 28, pp. 88-92. 
[23] F. Klocke, P. Vogtel, S. Gierlings, D. Lung, and D. Veselovac: Prod. Eng., 2013, vol. 7, pp. 593-600.

[24] R.J. Kamaladasa and Y.N. Picard: Microscopy, 2010, pp. 1583-1590.

[25] I.C. Noyan and J.B. Cohen: Residual stress measurement by diffraction and interpretation, pp. 117-130, Springer-Verlag New York Inc., New York, 1986.

[26] J.A. Bailey: Wear, 1977, vol. 42, pp. 297-303.

[27] M.C. Shaw: Metal Cutting Principles, pp. 432-479, Oxford University Press, New York, 2005.

[28] B.J. Griffiths: J. Tribol., 1987, vol. 109, pp. 525-530.

[29] J.M. Zhou, V. Bushlya, R.L. Peng, and J.E. Ståhl: Appl. Mech. Mater., 2012, vol. 117, pp. 1681-1688.

[30] J. Barry and G. Byrne: Mater. Sci. Eng. A, 2002, vol. 325, pp. 356-364.

[31] K. Jacobus, R.E. DeVor, and S.G. Kapoor: J. Manuf. Sci. Eng., 2000, vol. 122, pp. 20-31.

[32] P.S. Prevéy: Residual Stress in Design, Process and Materials Selections, pp. 11-19, ASM Metals Park, OH, 1987.

[33] N.A. Abukhshim, P.T. Mativenga, and M.A. Sheikh: Int. J. Mach. Tools Manuf., 2006, vol. 46, pp. 782-800. 
[34] L.M. Clarebrough, M.E. Hargreaves, and G.W. West: Proceedings of the Royal Society of London, Series A, Mathematical and Physical and Engineering Sciences, 1955, vol. 232, pp. 252270.

[35] O. Vöhringer: Advances in Surface Treatments, Technology-Applications-Effects, Pergamon Press, Oxford, 1987, vol. 4, pp. 367-396.

[36] Z. Bi, J. Dong, M. Zhang, L. Zheng, and X. Xie: Int. J. Miner. Metall. Mater., 2010, vol. 17, pp. 312-317.

[37] Z. Chen, R.L. Peng, P. Avdovic, J.M. Zhou, J. Moverare, F. Karlsson, and S. Johansson: MATEC Web of Conferences, vol. 14, no. 08002, pp. 1-6, EDP Sciences, 2014.

[38] J.F. Radavich: Superalloys 718, 625, 706 and Various Derivatives, pp. 409-415, TMS, 1997.

[39] X.J. Pang, D.J. Dwyer, M. Gao, P. Valerio, and R.P. Wei: Scr. Mater., 1994, vol. 31, pp. 345350.

[40] P. Lin, G. Palumbo, U. Erb, and K.T. Aust: Scr. Mater., 1995, vol. 33, pp. 1387-1392.

[41] D. Farkas: J. Phys. Condens. Matter, 2000, vol. 12, pp. R497.

[42] T.K. Hirsch, A.D.S. Rocha, F.D. Ramos, and T.R. Strohaecker: Metall. Mater. Trans. A, 2004, vol. 35, pp. 3523-3530. 


\section{Table \& Figure captions}

Tab. 1 Chemical composition in wt.\% of the investigated Inconel 718 forging

Fig. 1 (a) Microstructure of the Inconel 718 forging; (b) Carbides in the microstructure.

Fig. 2 Broached slot with a fir-tree profile and the white arrow points out the broached surface where the studies were performed.

Fig. 3 In-plane and out-plane residual stress components on the broached surface.

Fig. 4 Overview of the anomalies generated on the broached surface.

Fig. 5 ECCI image showing the plastically deformed microstructure beneath the broached surface. Broaching direction is pointed out by $V c$.

Fig. 6 Cracked carbides beneath the broached surface and surface cracking associated with the cracked carbide. Broaching direction is pointed out by $V c$.

Fig. 7 Comparison of the nano-hardness distribution as a function of depth beneath the broached surface and the LAGB density depth profile measured by EBSD. The LAGB is defined when the misorientation between two neighboring pixels with a center-to-center distance of $0.5 \mu \mathrm{m}$ in the EBSD mapping falls within the range of 1deg to $10 \mathrm{deg}$.

Fig. 8 Residual stress depth profile of the as-broached specimen.

Fig. 9 (a) Plastically deformed microstructure beneath the broached surface as a reference; microstructural alterations after thermal exposure (b) $723 \mathrm{~K}\left(450{ }^{\circ} \mathrm{C}\right), 3000$ hours; (c) $823 \mathrm{~K}(550$ $\left.{ }^{\circ} \mathrm{C}\right), 30$ hours; (d) $823 \mathrm{~K}\left(550{ }^{\circ} \mathrm{C}\right), 300$ hours; (e) $823 \mathrm{~K}\left(550{ }^{\circ} \mathrm{C}\right), 3000$ hours; (f) $923 \mathrm{~K}\left(650{ }^{\circ} \mathrm{C}\right)$, 30 hours; (g) $923 \mathrm{~K}\left(650{ }^{\circ} \mathrm{C}\right), 300$ hours; (h) $923 \mathrm{~K}\left(650{ }^{\circ} \mathrm{C}\right)$, 3000 hours. Broaching direction is pointed out by $V c$.

Fig. $10 \alpha$-Cr identification by a combination of EBSD mapping and EDS mapping. The mapping was made on the recrystallized surface layer of the specimen with $923 \mathrm{~K}\left(650{ }^{\circ} \mathrm{C}\right)$ heat treatment for 300 hours, as marked in the secondary electron image. Note that $\alpha$-Cr appears as small bright particles in the secondary electron image, instead of the small dark particles as observed in ECCI images as shown in Fig. 9.

Fig. $11 \alpha$-Cr free zone close to the broached surface (a) $723 \mathrm{~K}\left(450{ }^{\circ} \mathrm{C}\right), 3000$ hours; (b) $823 \mathrm{~K}$ $\left(550{ }^{\circ} \mathrm{C}\right), 3000$ hours; (c) $923 \mathrm{~K}\left(650^{\circ} \mathrm{C}\right), 3000$ hours. White dash lines point out the boundary of the $\alpha$-Cr free zone beneath the surface.

Fig. 12 Summary of the changes in surface residual stresses and surface FWHM for all annealing conditions applied.

Fig. 13 ECCI high-resolution image showing a nano-crystalline microstructure of the surface layer for the as-broached sample. Broaching direction is pointed out by Vc. 
Fig. 14 Depth profiles of the two out-plane shear components ( $\sigma_{13}$ and $\sigma_{23}$ ) for the as-broached sample.

Fig. 15 Annealing twin formed as growth accidents during the surface recrystallization in the specimen subjected to $923 \mathrm{~K}\left(650{ }^{\circ} \mathrm{C}\right)$ thermal exposure for 3000 hours. EBSD mapping was made on the recrystallized surface layer as marked in the secondary electron image.

Fig. 16 Annihilation of LAGBs in the surface layer for the specimen been heated at $923 \mathrm{~K}\left(650{ }^{\circ} \mathrm{C}\right)$ for 3000 hours (b) in comparison with the as-broached specimen (a). Note that for the as-broached specimen, substantial zero solutions were recorded close to the surface as the microstructure is highly deformed, and thus the crystallographic orientation information cannot be identified. Broaching direction is pointed out by $V c$. Both two mappings were taken with a step size of 0.05 $\mu \mathrm{m}$ and the LAGB is defined when the misorientation between two neighboring pixels in EBSD mappings falls within the range of $1 \mathrm{deg}$ to $10 \mathrm{deg}$.

Fig. 17 Residual stress depth profile of the broached specimen after 30 hours thermal exposure at 823K $\left(550{ }^{\circ} \mathrm{C}\right)$.

Fig. 18 Stress relaxation for the specimens heated at $923 \mathrm{~K}\left(650{ }^{\circ} \mathrm{C}\right)$ for 300 hours and 3000 hours: (a) $\sigma_{11}$ and (b) $\sigma_{22}$.

Fig. 19 Secondary electron image of the Cr-rich oxide scale (pointed out by the white arrow) formed on the top of the broached surface after 3000 hours thermal exposure at $923 \mathrm{~K}\left(650{ }^{\circ} \mathrm{C}\right)$.

Fig. 20 Comparison of the Cr content depth profile for a polished specimen, without any broaching effect, and the broached specimen. Both two specimens were heat treated at $923 \mathrm{~K}\left(650{ }^{\circ} \mathrm{C}\right)$ for 300 hours. Note that the measurement was conducted on the metallic alloy below the oxide scale. 


\begin{tabular}{|c|c|c|c|c|c|c|c|c|c|c|c|c|c|c|}
\hline Alloy & wt. \% & Fe & Ni & Cr & Mo & Nb & Ti & Al & Co & Ta & Cu & C & Si & Mn \\
\hline Inconel 718 & Min. & Bal. & 50 & 17 & 2.8 & 4.75 & 0.65 & 0.2 & & & & & & \\
\cline { 2 - 13 } & Max. & & 55 & 21 & 3.3 & 5.5 & 1.15 & 0.8 & 1 & 0.05 & 0.3 & 0.08 & 0.35 & 0.35 \\
\hline
\end{tabular}




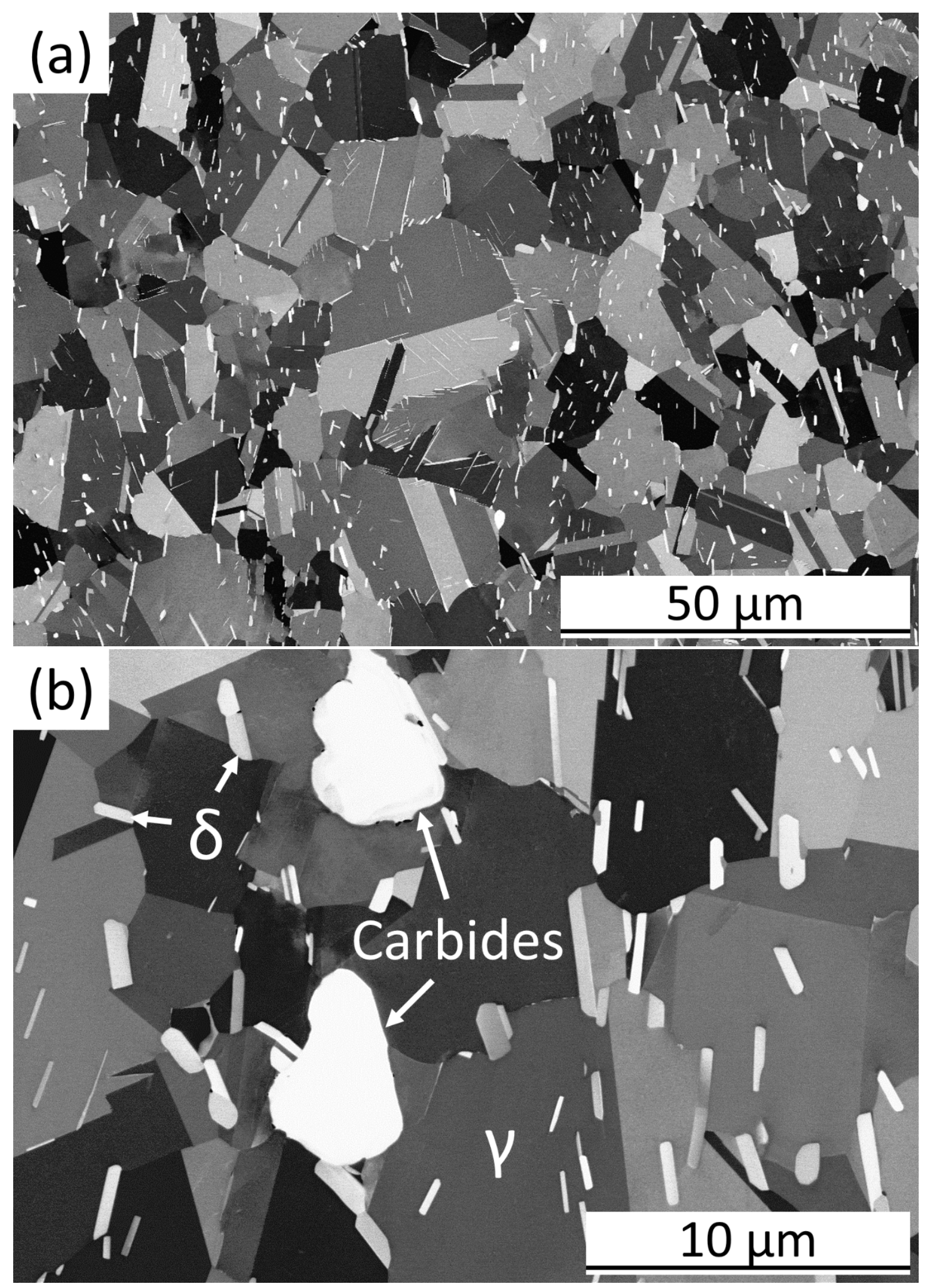

Figure 1 


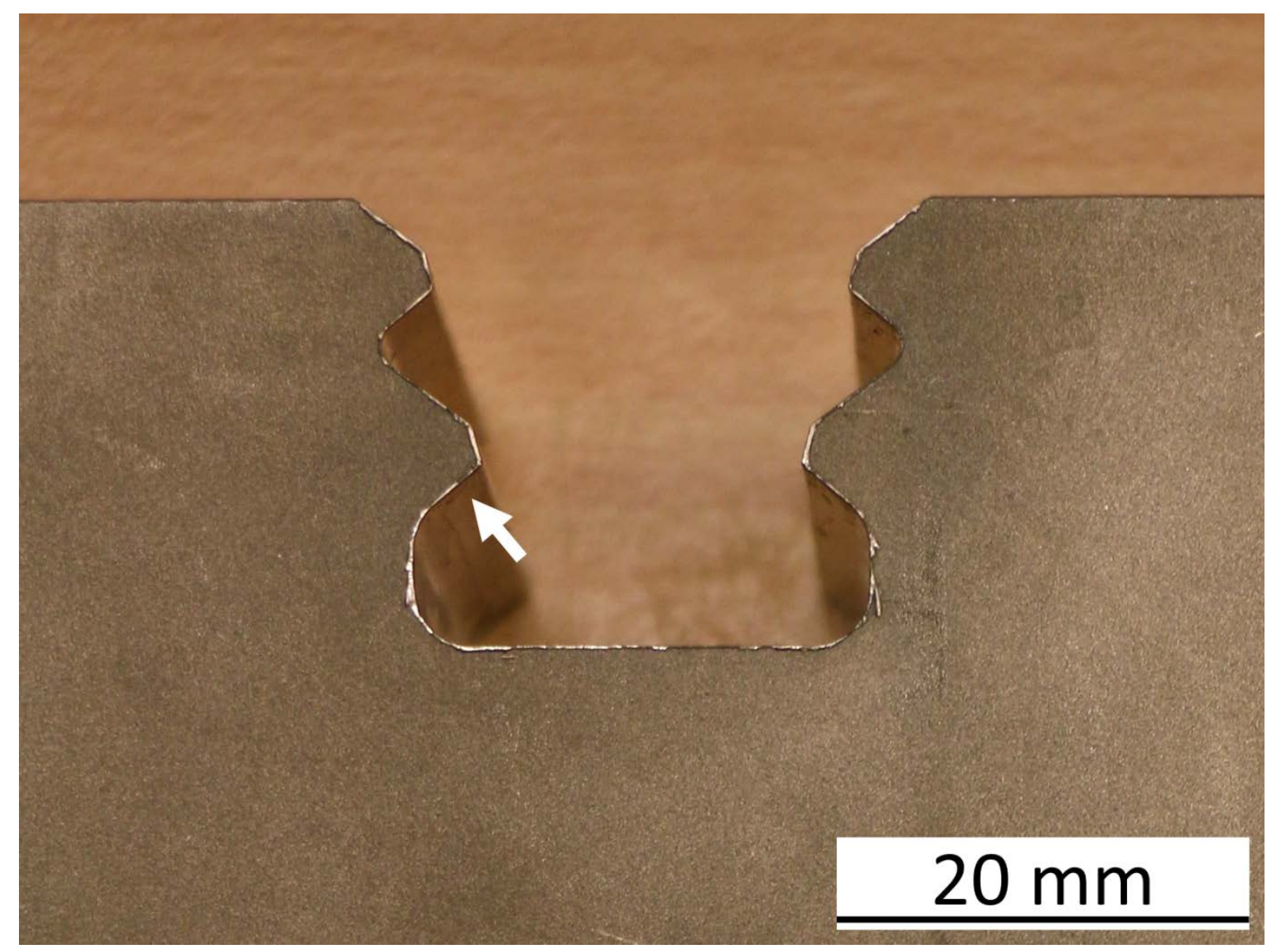

Figure 2 


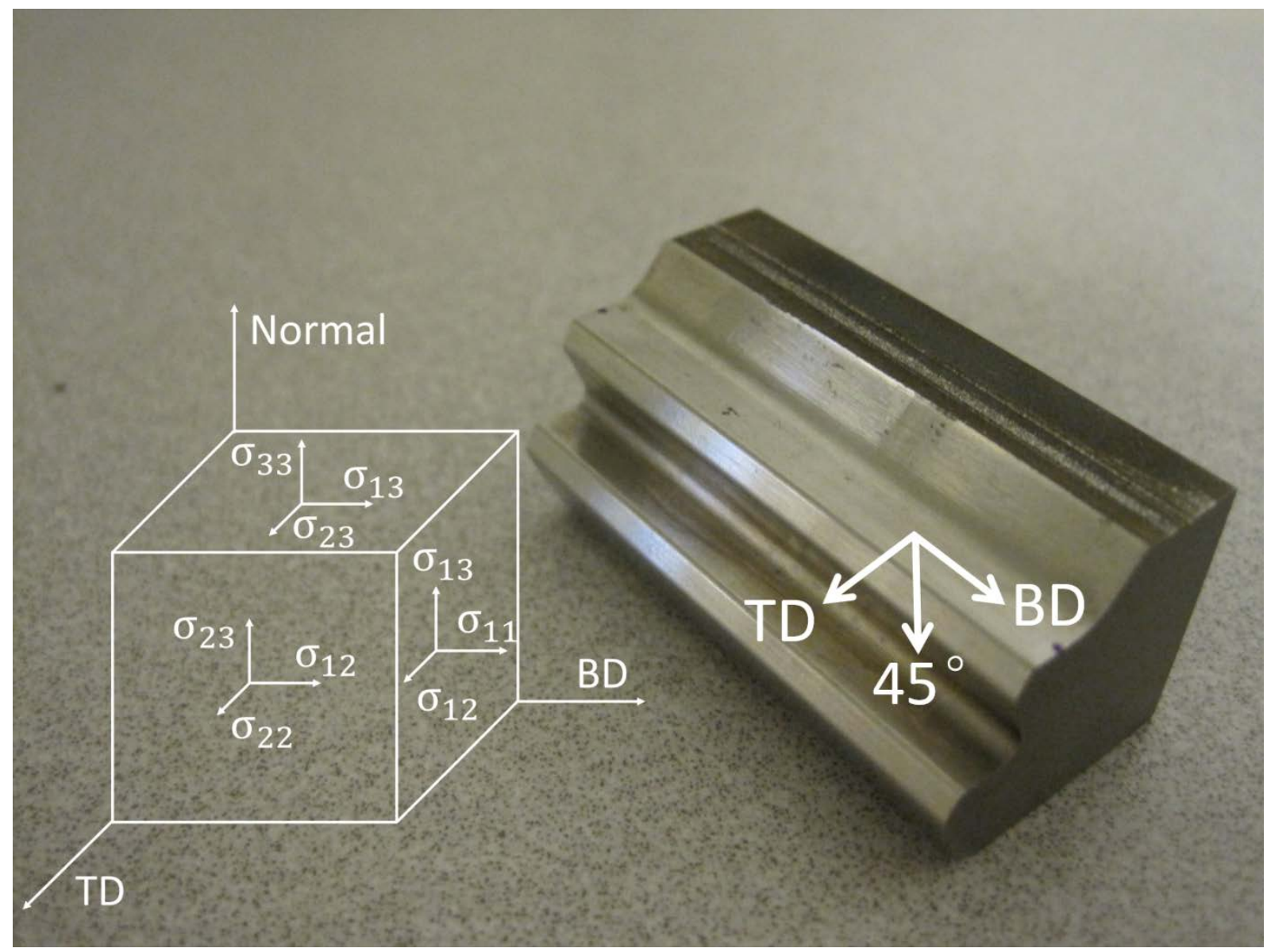

Figure 3 


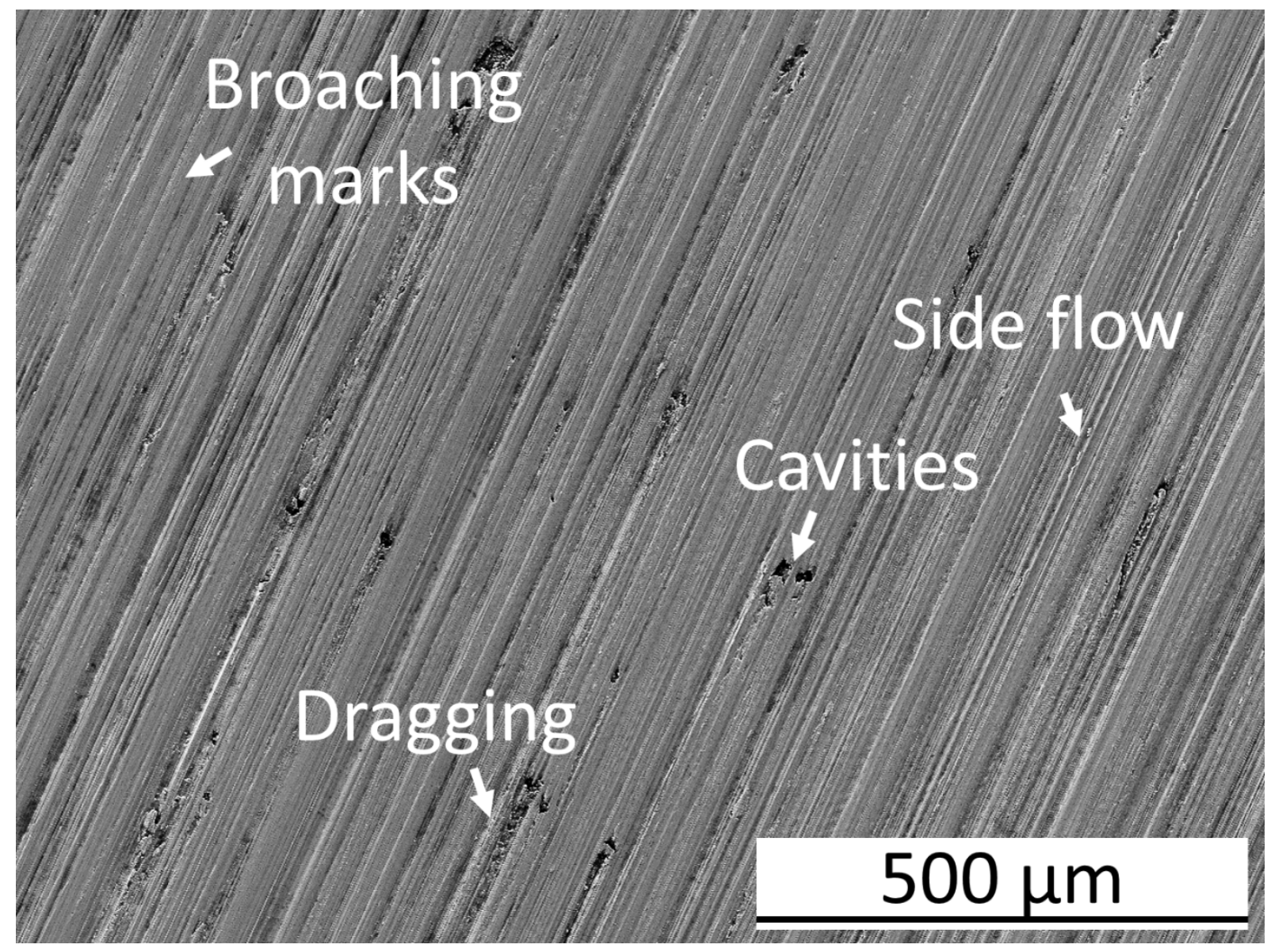

Figure 4 


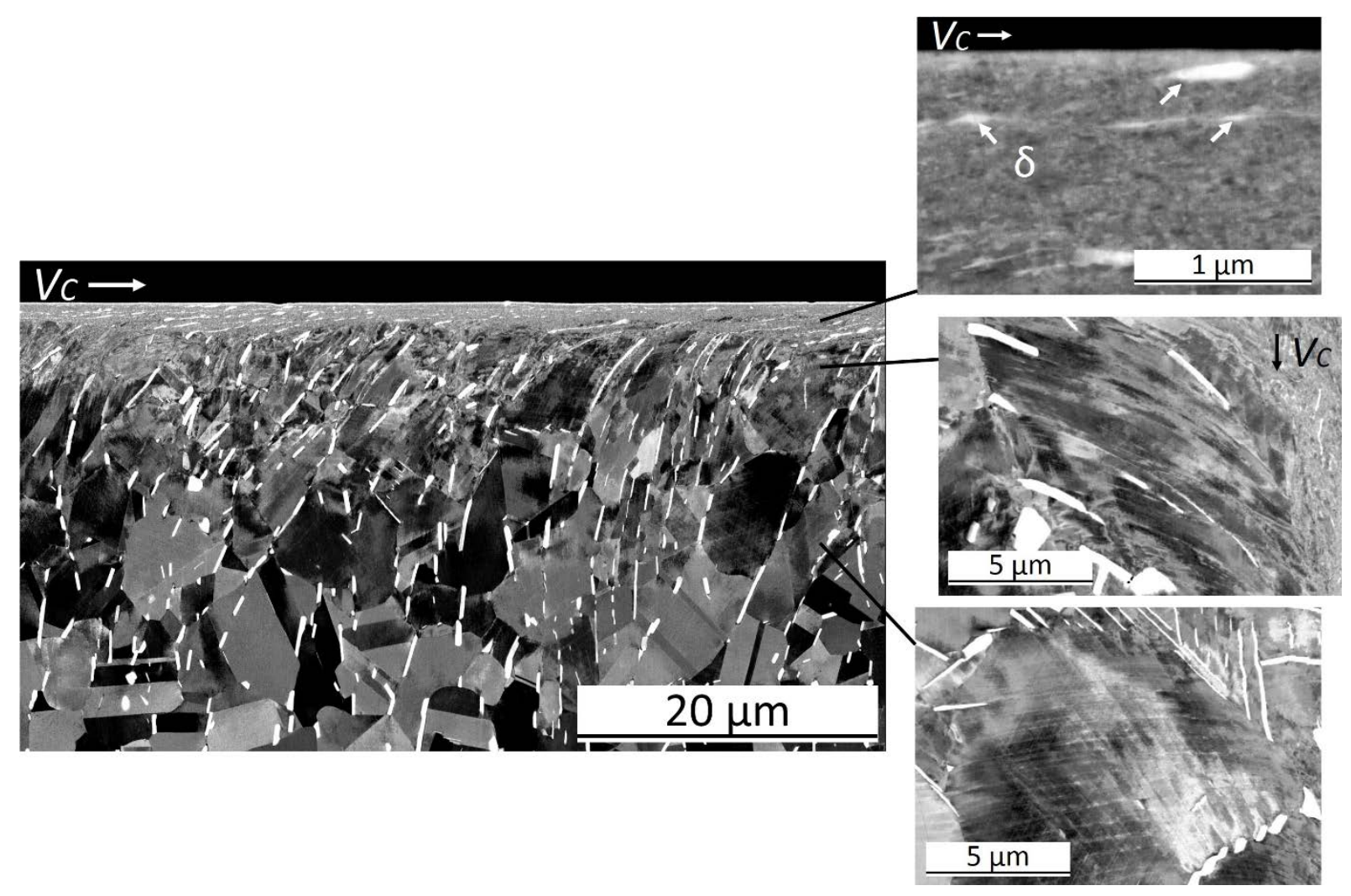

Figure 5

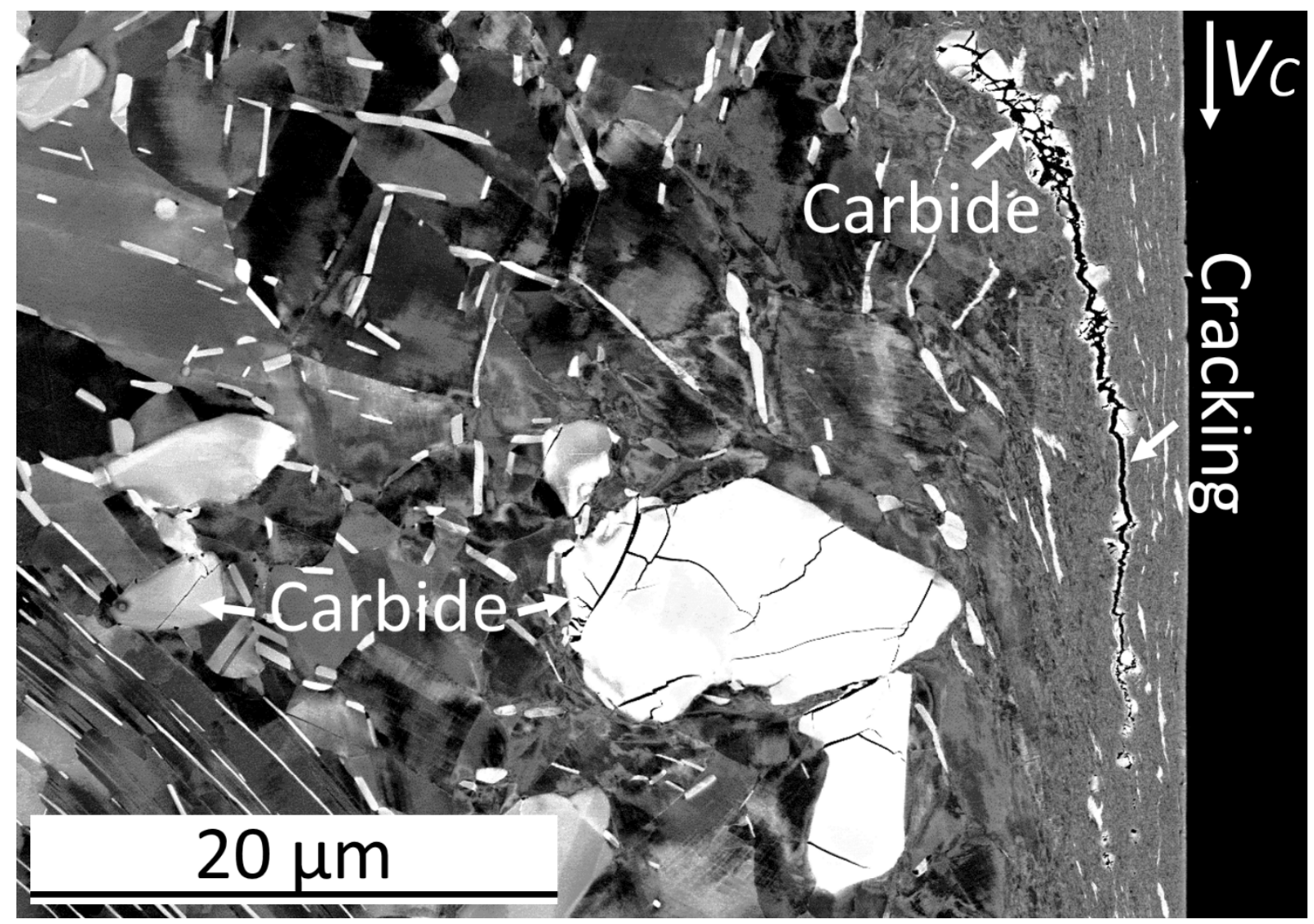

Figure 6 


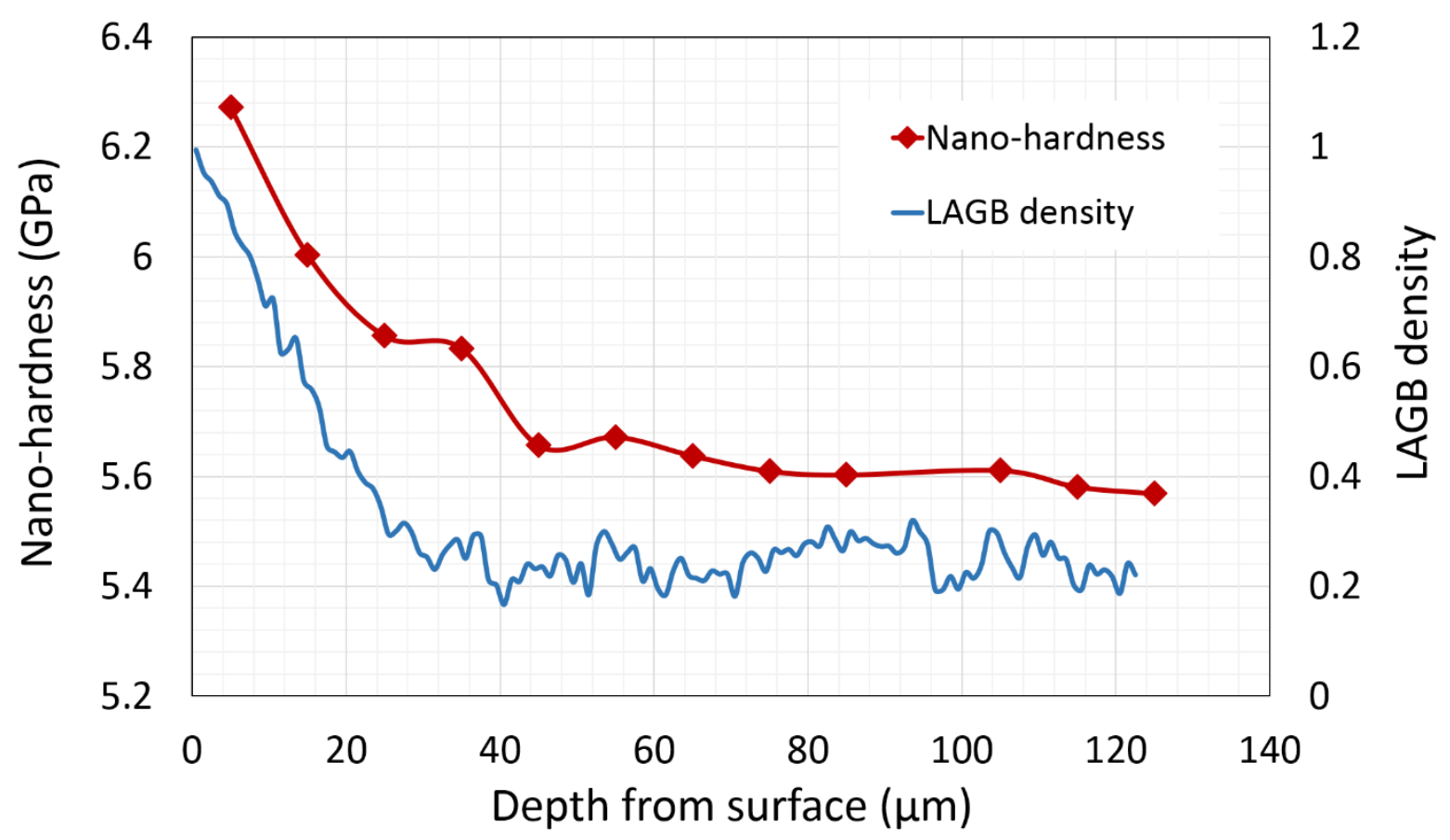

Figure 7

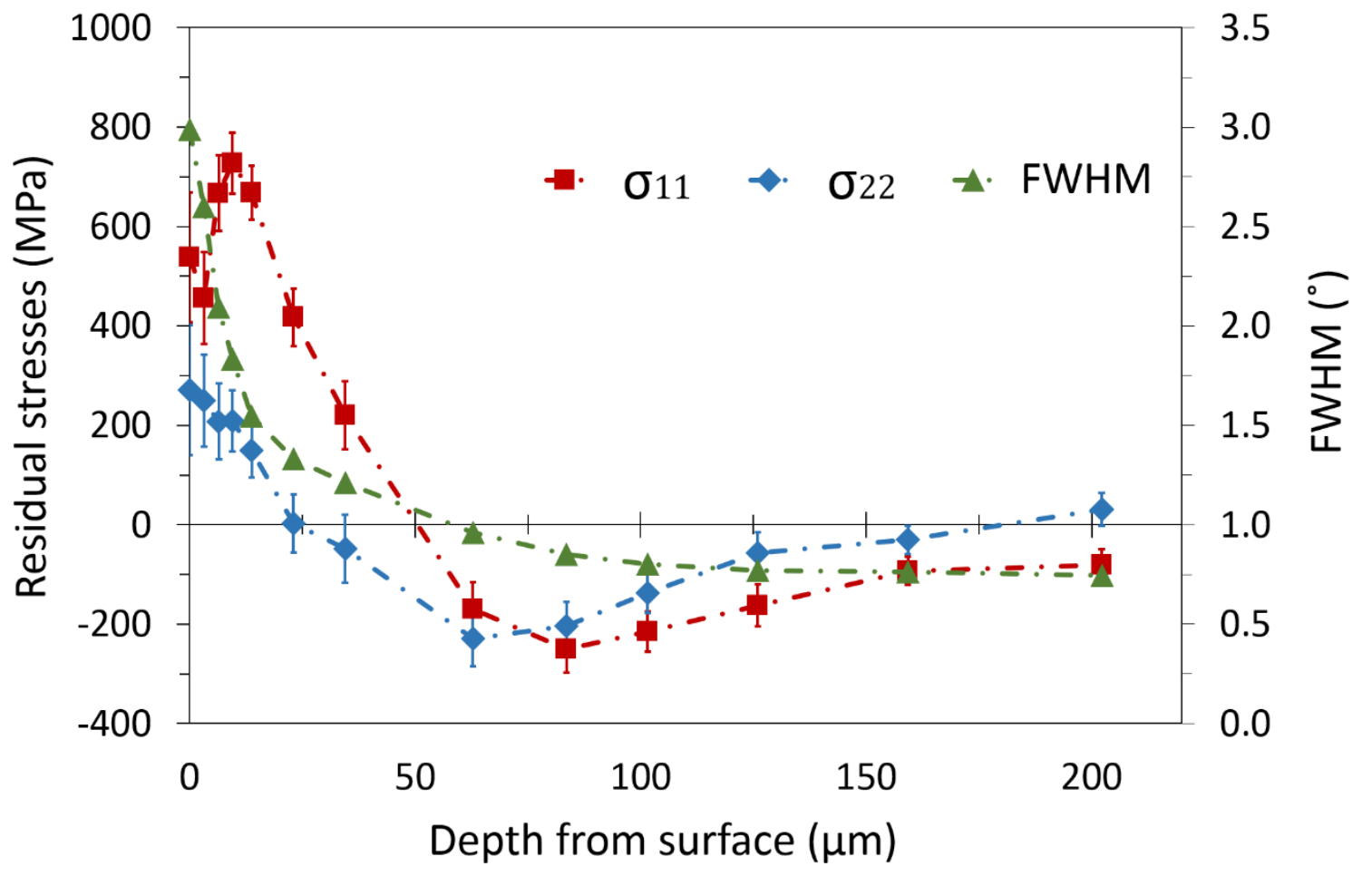

Figure 8 


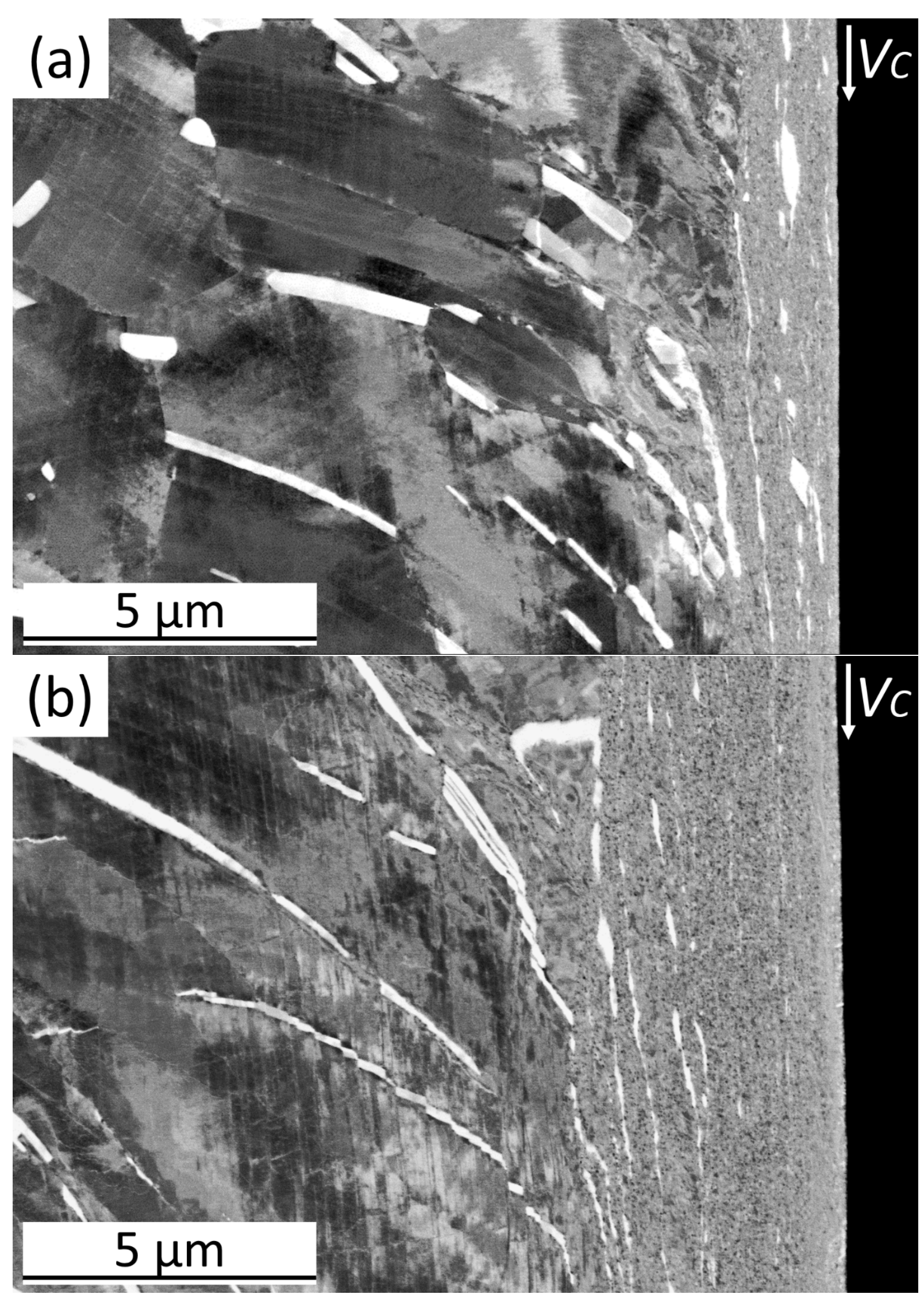




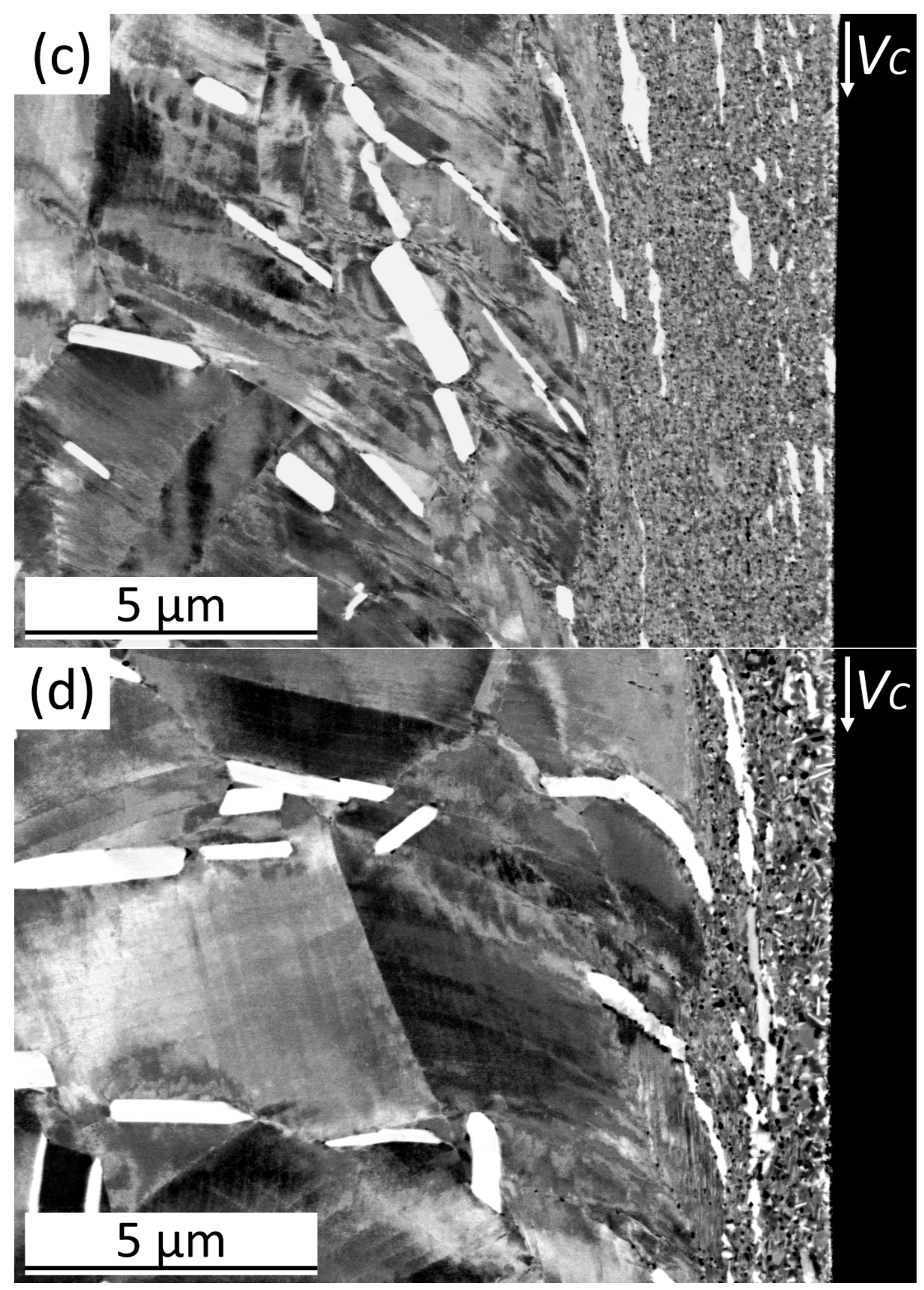




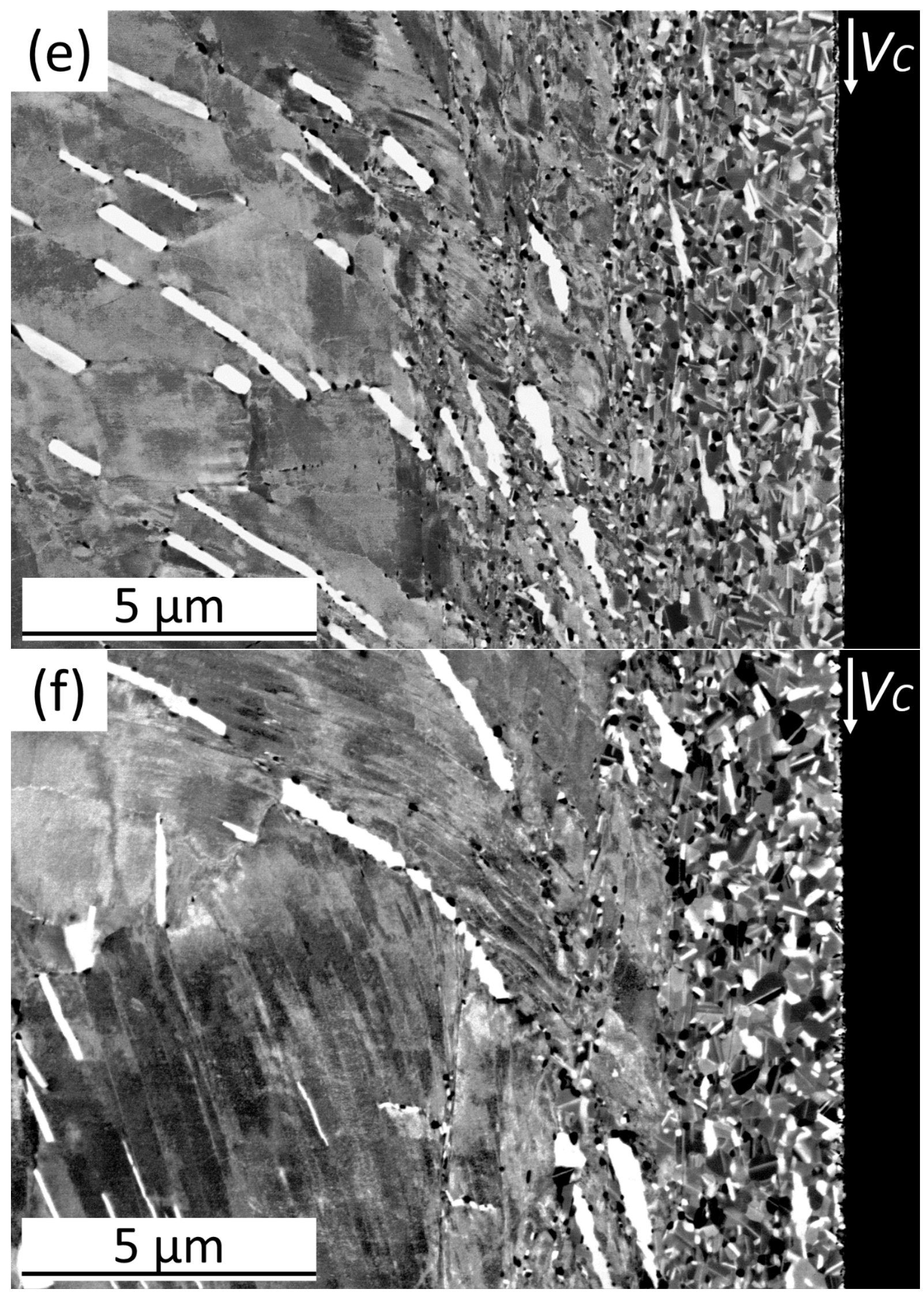




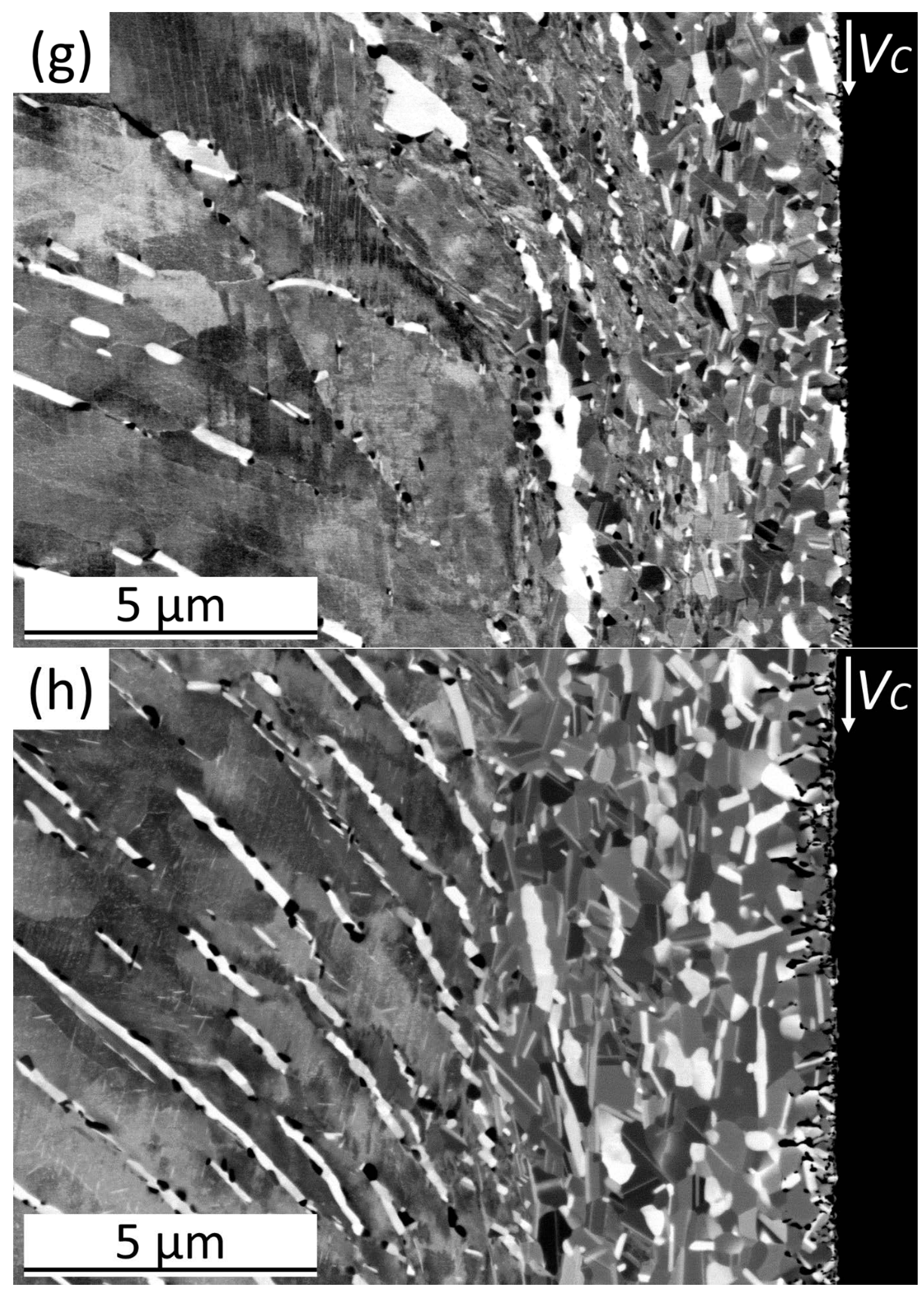

Figure 9 


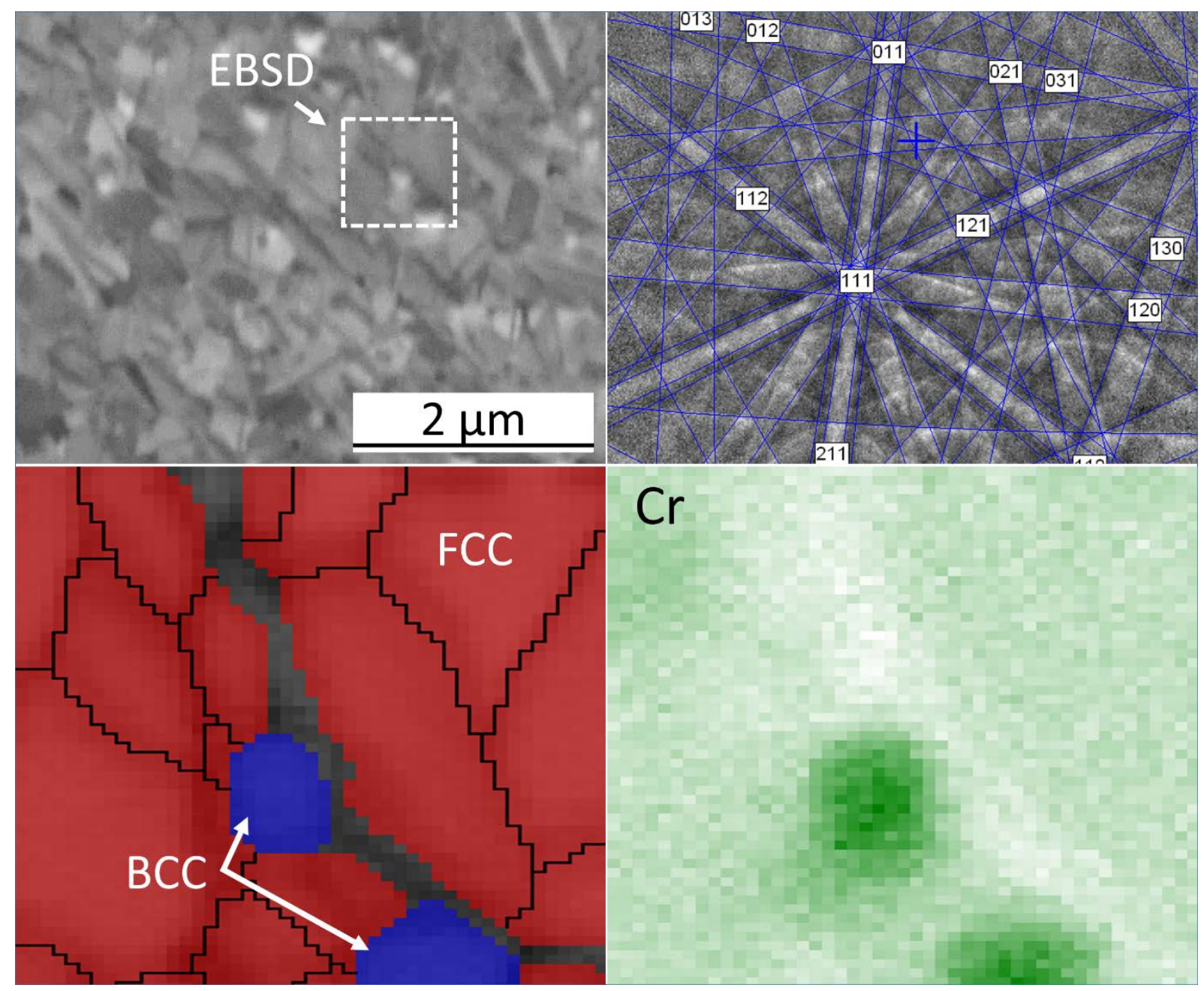

Figure 10 







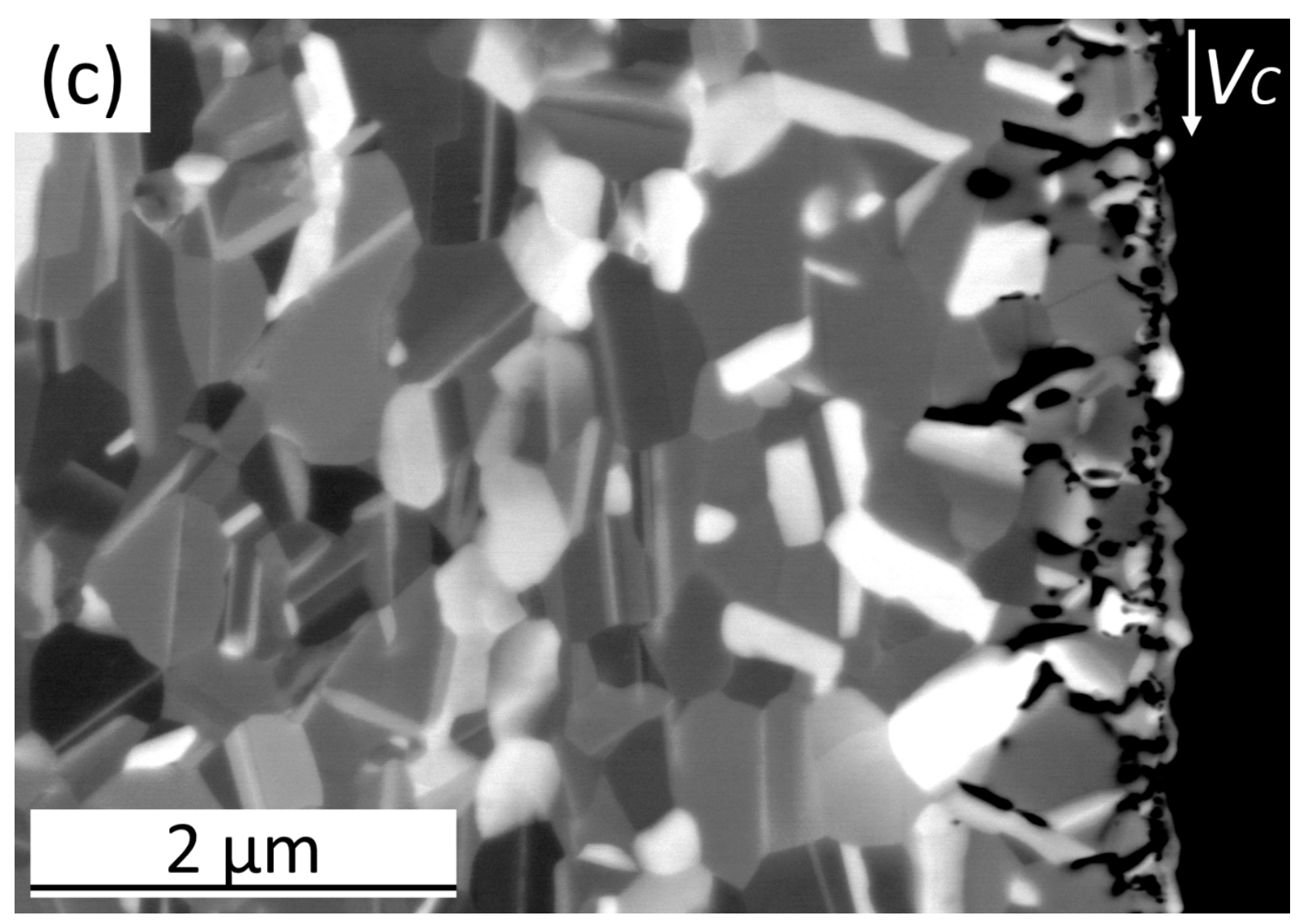

Figure 11

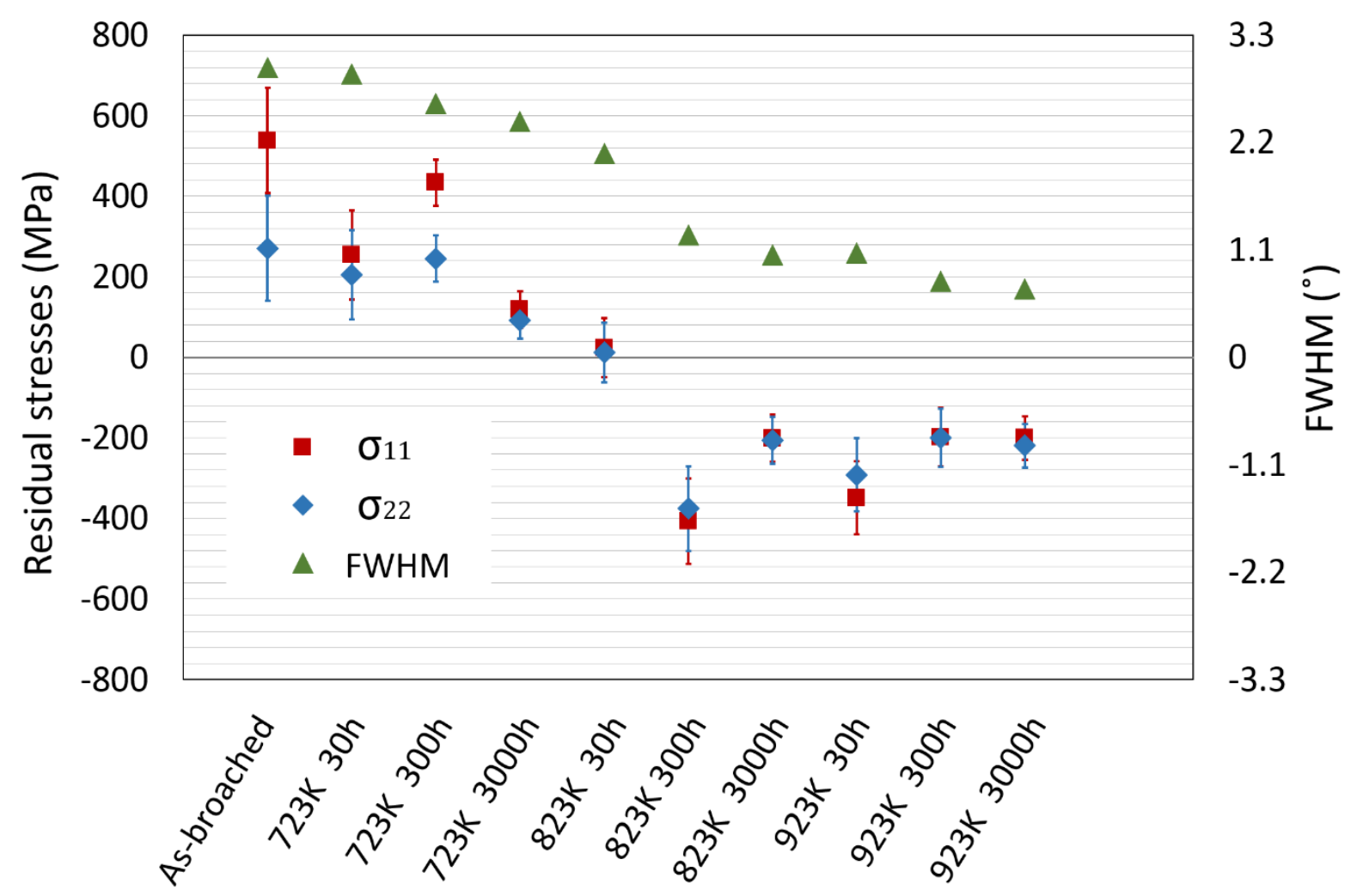

Figure 12 


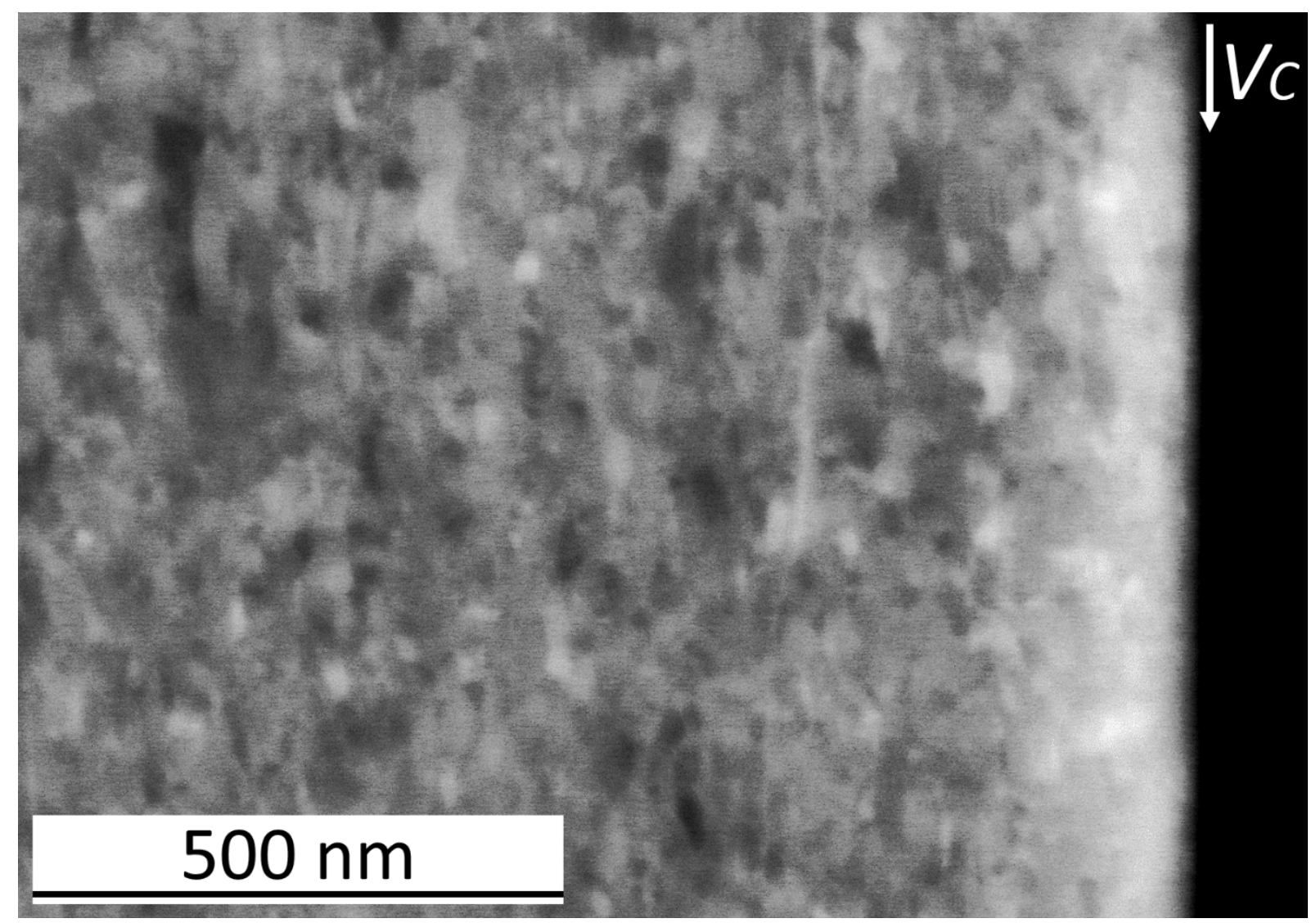

Figure 13

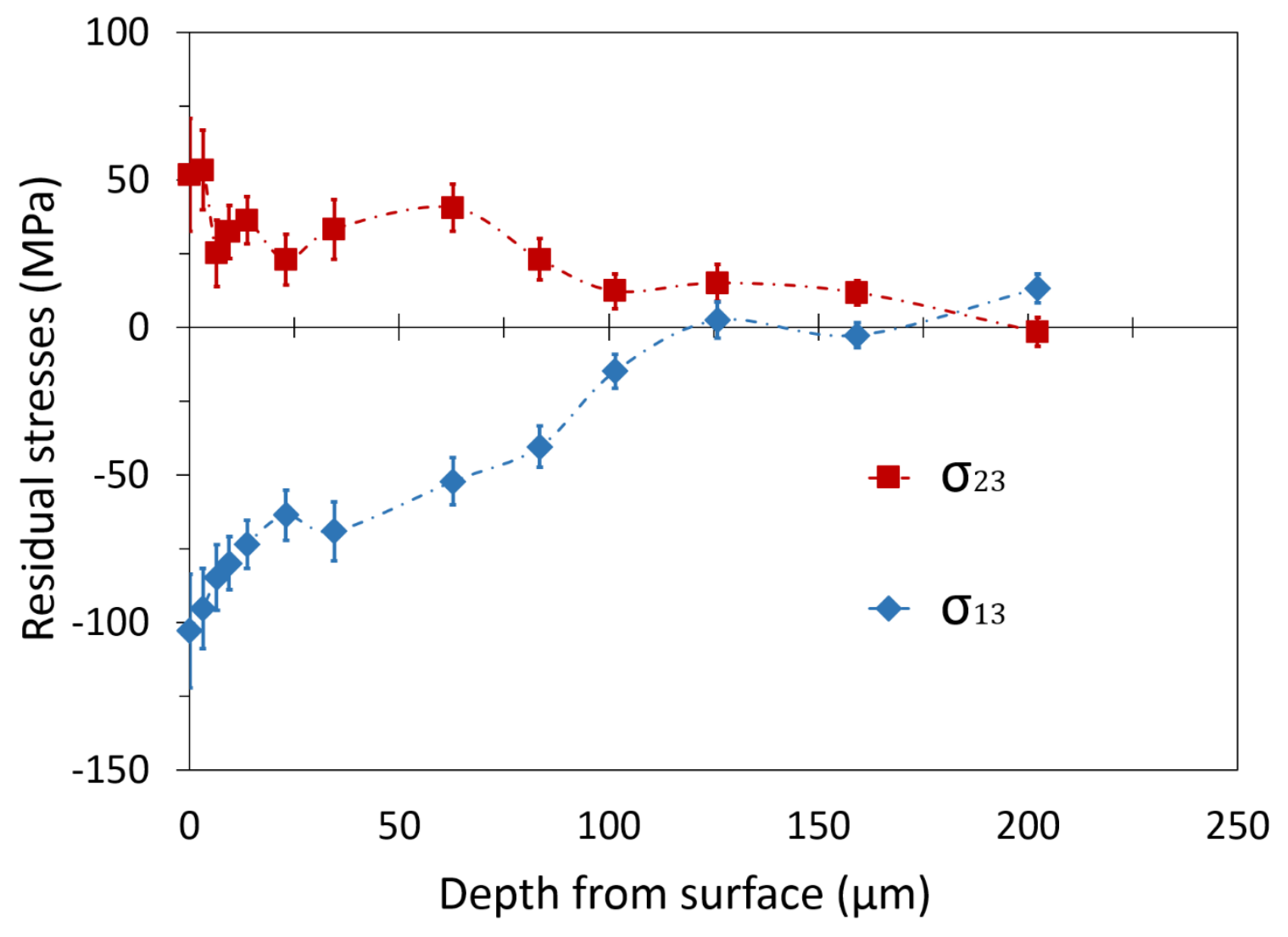

Figure 14 

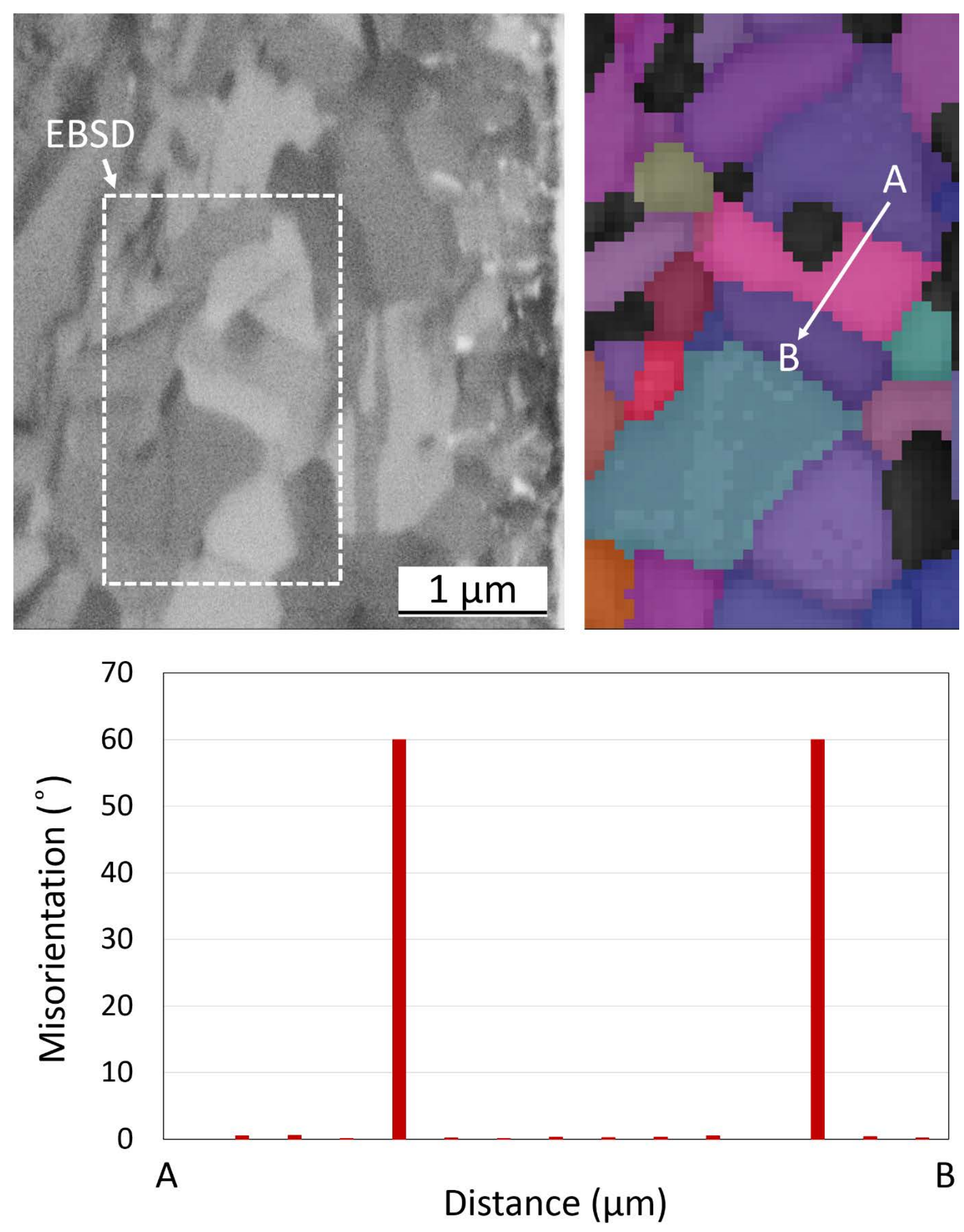

Figure 15 


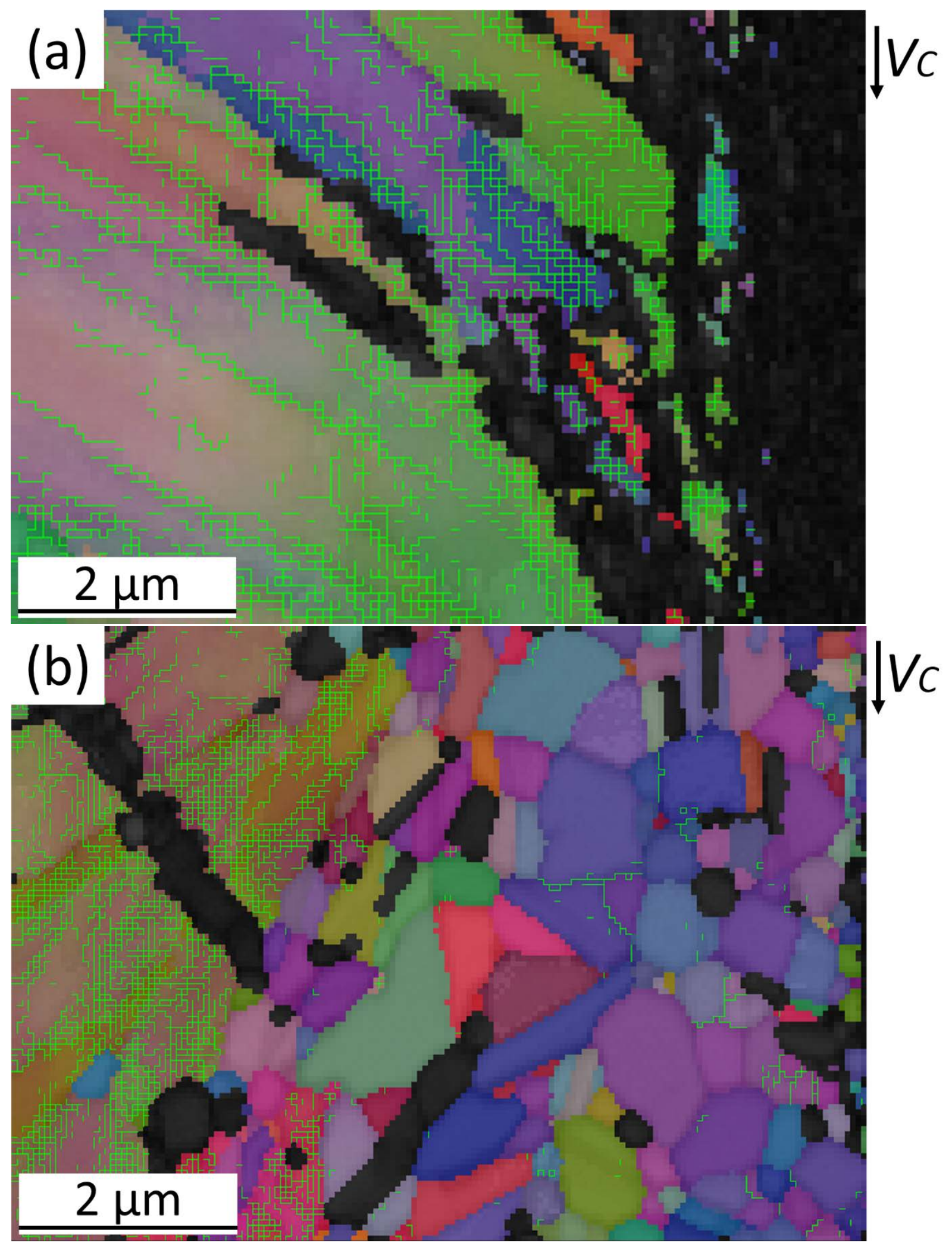

Figure 16 


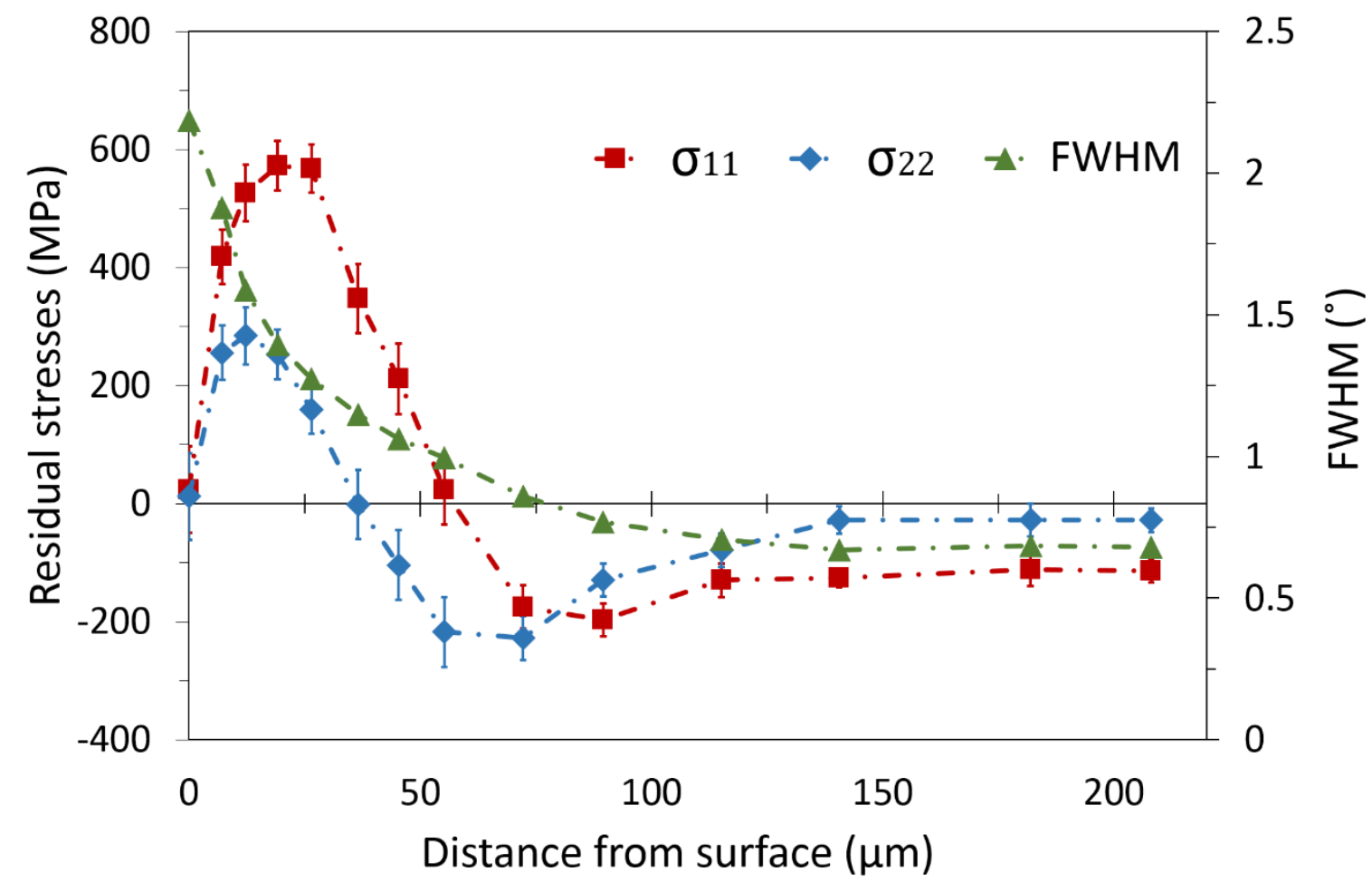

Figure 17 

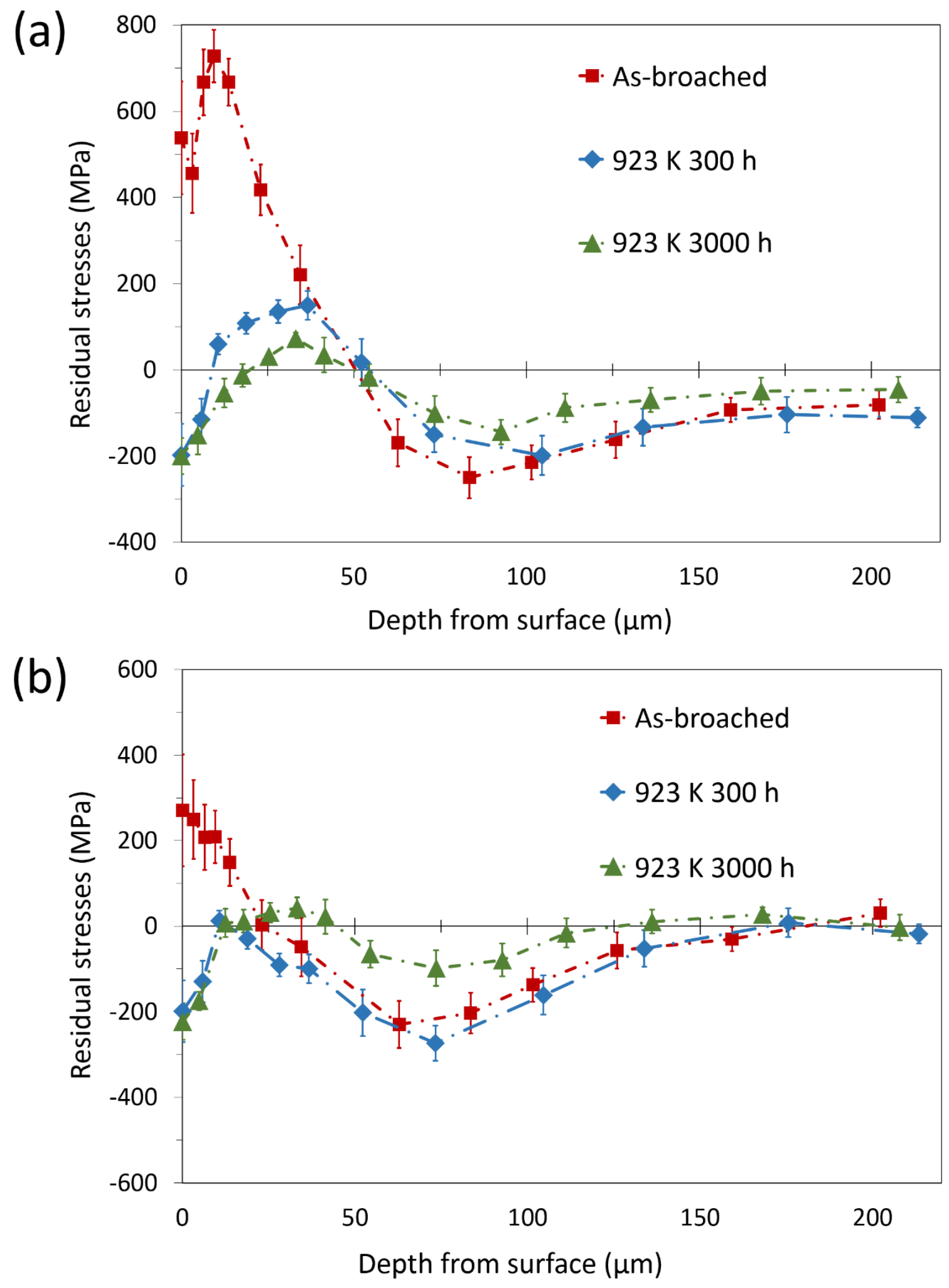

Figure 18 


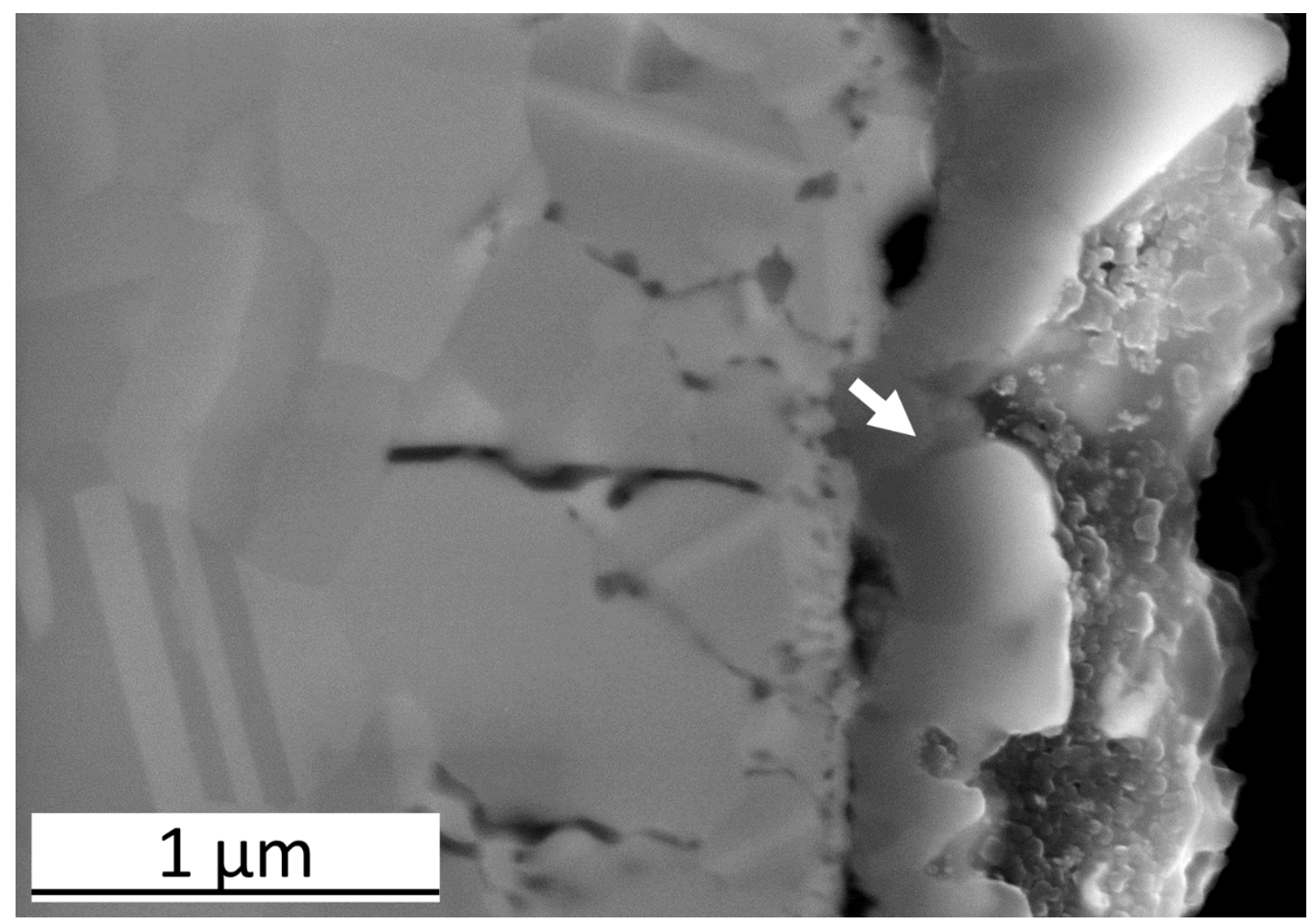

Figure 19

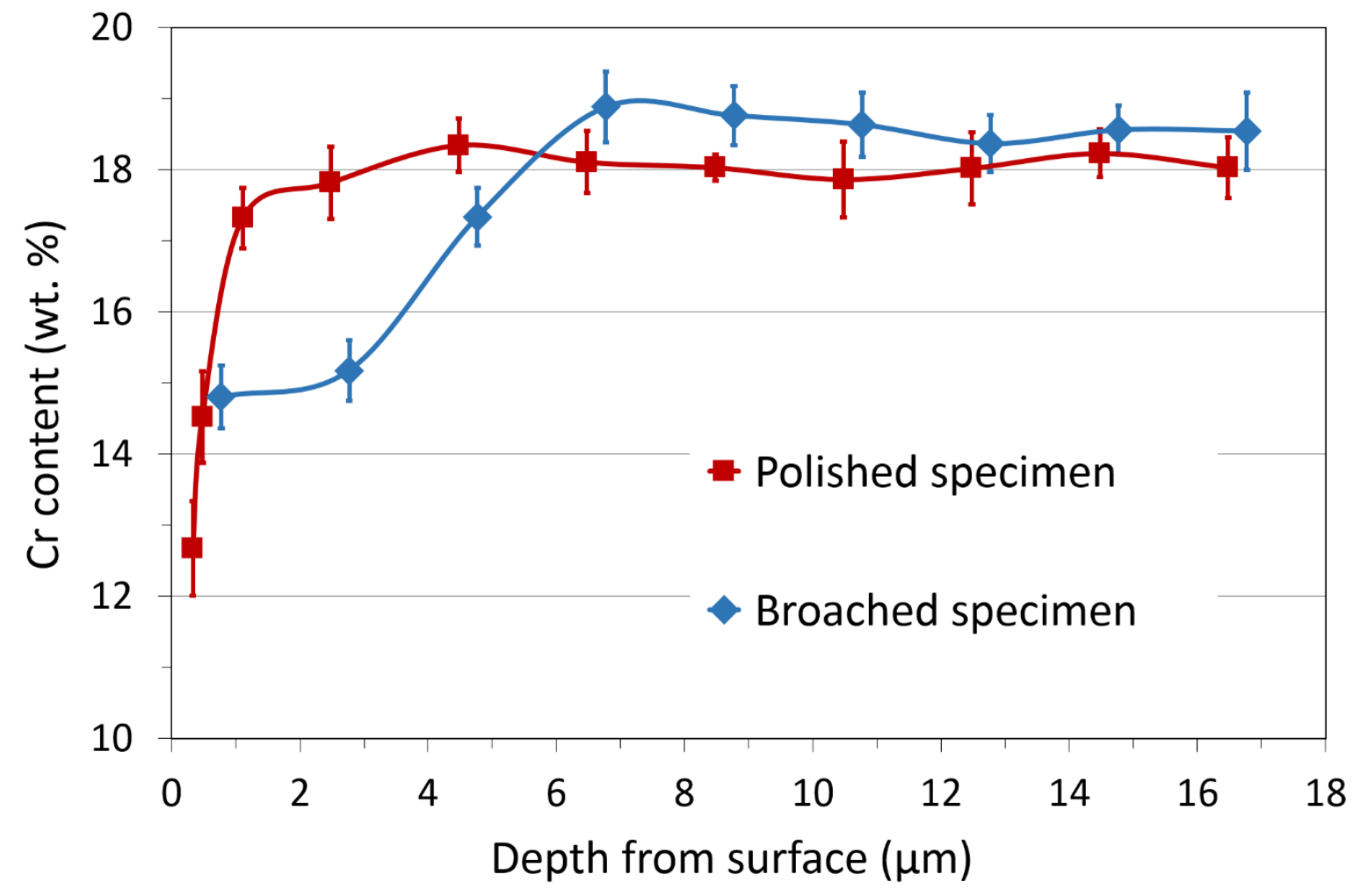

Figure 20 